Neuronal expression by Boolean Exclusion

21 Tyler Vahedi-Hunter ${ }^{* 1}$, Teresa Ubina ${ }^{* 1}$, Akshay Gupta ${ }^{1}$, Wenny Wong ${ }^{1}$, Will Agnew-

22 Svoboda $^{1}$, Vijayalakshmi Santhakumar ${ }^{1}$, Martin M. Riccomagno ${ }^{1}$

23

Corresponding Author: Martin M. Riccomagno, martinmr@ucr.edu.

\section{ExBoX: a simple Boolean exclusion strategy to drive expression in neurons}

Running title: Neuronal expression by Boolean Exclusion

${ }^{1}$ Neuroscience Graduate Program, Department of Molecular, Cell \& Systems Biology, University of California, Riverside, CA, USA

*Authors contributed equally to this work

33 
Neuronal expression by Boolean Exclusion

1 Keywords: Boolean logic, recombinases, combinatorial expression, intersectional

2 approaches, Cre, Flp, Adeno-Associated Virus.

\section{Abstract}

The advent of modern single-cell biology has revealed the striking molecular

5 diversity of cell populations once thought to be more homogeneous. This newly

6 appreciated complexity has made intersectional genetic approaches essential to

7 understanding and probing cellular heterogeneity at the functional level. Here we build

8 on previous knowledge to develop a simple AAV-based approach to define specific

9 subpopulations of cells by Boolean exclusion logic (AND NOT). This Expression by

10 Boolean Exclusion (ExBoX) system encodes for a gene of interest which is turned ON

11 by a particular recombinase (Cre or FlpO) and turned OFF by another. ExBoX allows for

12 the specific transcription of a gene of interest in cells expressing only the activating

13 recombinase, but not in cells expressing both. We show the ability of the ExBoX system

14 to tightly regulate expression of fluorescent reporters both in vitro and in vivo, and

15 further demonstrate the powerful adaptability of the system by achieving expression of a

16 variety of virally-delivered coding sequences in the mouse brain. This simple strategy

17 will expand the molecular toolkit available for cell- and time-specific gene expression in

18 a variety of organisms and systems. 
bioRxiv preprint doi: https://doi.org/10.1101/2020.07.28.224691; this version posted July 30, 2020. The copyright holder for this preprint (which

was not certified by peer review) is the author/funder, who has granted bioRxiv a license to display the preprint in perpetuity. It is made available under aCC-BY-NC-ND 4.0 International license.

\section{Neuronal expression by Boolean Exclusion}

\section{Abbreviations:}

2 Hemagglutinin (HA)

3 Adeno-Associated Virus (AAV)

4 Double-floxed Inverse Orientation (DIO)

5 Dentate Gyrus (DG)

6 Gene Of Interest (GOI)

7

8 
Neuronal expression by Boolean Exclusion

\section{Introduction}

Advancements in our understanding of the mechanisms underlying biological

3 processes have been greatly dependent on the development of new genetic tools. A big

4 breakthrough in mammalian genetics was the discovery and implementation of

5 homologous recombination to generate loss-of-function alleles in mice (Capecchi,

6 1989). The introduction of recombinases as genetically encoded tools, in combination

7 with conditionally targeted genetic alleles, made the control of genetic deletion in a

8 tissue-specific manner possible (Gu et al, 1994; Tsien et al, 1996). With the availability

9 of recombinase-dependent systems, region-specific gene knockouts and progenitor

10 tracing have now become routine experimental strategies in mouse genetics (Branda \&

11 Dymecky, 2004).

Although cell diversity has always been appreciated in biology, single-cell

13 profiling has revolutionized the way we think about certain organs by uncovering cell

14 heterogeneity in populations that were once thought to display less complexity

15 (Darmanis et al, 2015). Our ability to appreciate cellular complexity is currently limited

16 by the available tools to label and manipulate cells with increased specificity. One way

17 to overcome this limitation is to simply expand the pool of tissue- and population-

18 specific recombinase lines. This requires the generation and characterization of

19 independent transgenic recombinase mouse lines for each newly discovered cell

20 population. A complementary approach that can take advantage of preexisting

21 transgenic lines is to incorporate genetically encoded intersectional approaches

22 (Awatramani et al, 2003). In comparison to conventional transgenic strategies that 
Neuronal expression by Boolean Exclusion

1 select cellular targets based on expression of one particular promoter or driver,

2 intersectional approaches provide tighter specificity by selecting targets based on the

3 overlapping or sequential expression of multiple recombinases (Jensen \& Dymecki,

4 2014). These intersectional strategies based on the combinatorial expression of two

5 recombinase systems (Cre/lox and Flp/FRT) were first used in the mouse to perform

6 fate mapping of previously elusive neural progenitors (Dymecki, Ray, \& Kim 2010).

7 Intersectional approaches are not only able to label subpopulations with greater

8 specificity, but also make a variety of Boolean logic operations (AND, NOT, OR)

9 available (Daigle et al., 2019; Plummer et al, 2015). With multiple recombinase systems

10 driving the expression of reporter genes, targeting of subpopulations of cells can be

11 achieved through intersectional (expressing all drivers) and subtractive (lacking

12 expression of one or more drivers) strategies (Farago et al, 2006).

Viral vectors offer an alternative approach to driving conditional and

14 intersectional expression (Schnütgen et al, 2003; Atasoy et al, 2008; Gradinaru, 2010;

15 Fenno et al, 2014). Strictly genetically encoded strategies have clear advantages over

16 surgically introduced viral vectors, like non-invasiveness and broad applicability in hard

17 to reach tissues during otherwise inaccessible embryonic stages (Jensen \& Dymecki,

18 2014). However, viral expression systems can be extremely powerful given the ease of

19 generation and the additional level of control one can gain by selecting the region and

20 time of injection (Zhang et al, 2007; Sternson et al, 2015). There are now multiple

21 versions of recombinase-dependent AAVs for recombinases like Cre, Flp, and DRE

22 (Atasoy et al, 2008; Saunders et al, 2012; Xue, Atallah, \& Scanziani, 2014). More 
bioRxiv preprint doi: https://doi.org/10.1101/2020.07.28.224691; this version posted July 30, 2020. The copyright holder for this preprint (which

was not certified by peer review) is the author/funder, who has granted bioRxiv a license to display the preprint in perpetuity. It is made available under aCC-BY-NC-ND 4.0 International license.

Neuronal expression by Boolean Exclusion

1 recently, systems for intersectional expression driven by AAVs have also been

2 developed (Kakava-Georgiadou et al, 2019; Fenno et al, 2014). Combination of these

3 viral and genetically-encoded approaches will ultimately be essential to understand

4 whether newly discovered molecular diversity within cell populations amounts to any

5 notable phenotypic difference in terms of cellular structure and function.

In addition to being able to parse out functional diversity, there is an interest in

7 the field of developmental biology in being able to specifically turn genes ON and OFF

8 during defined developmental windows or critical periods (Wiesel \& Hubel,1963;

9 Kozorovitskiy et al, 2012). Intersectional approaches using Boolean negation/exclusion

10 could provide a solution to this problem: a gene of interest could be turned ON by a

11 particular recombinase at a particular time point, while turned OFF later (AND NOT) by

12 a different recombinase (Table 1). Although a sophisticated system for AAV-driven

13 expression using exclusion logic has been generated elsewhere (Fenno et al, 2014), the

14 existing vectors have limitations in terms of being unnecessarily long and intricate in

15 design, somewhat restricting their applicability. In this study we describe the design and

16 characterization of an alternative expression system governed by Boolean exclusion

17 logic and driven by a single AAV. The newly developed vectors are simpler in design

18 and smaller in size, allowing for expression of longer genes of interest (GOI). As proof

19 of principle, we validated the system in neuronal populations, and also generated tools

20 for regulating neuronal activity in vivo. 
Neuronal expression by Boolean Exclusion

\section{Results}

Design and construction of a combinatorial expression system using Boolean exclusion: CreOn-FIpOff ExBoX

To control expression and label subsets of cells with greater specificity using Cre and FLP recombinases, we set out to develop a simple AAV-based expression system governed by Boolean Exclusion logic (Expression by Boolean Exclusion or ExBoX). We

7 first generated a system in which expression of a coding sequence of interest is turned

8 ON by Cre recombinase and turned OFF by Flp recombinase: CreOn-FlpOff (Table 1).

9 The CreOn-FlpOff vector was designed to contain a cassette with a coding sequence

10 (CDS) of interest in-frame with a hemagglutinin tag (HA), P2A site, and EGFP reporter

11 inverted with respect to a promoter. The promoter chosen for these experiments was

12 that of human Synapsin I, which is a well characterized postmitotic neuronal promoter

13 (Glover et al., 2002). The inverted cassette is flanked by Frt sites, and double-lox sites

14 (lox2722 and loxP) in inverse orientation (DIO) (Schnütgen et al., 2003) (Figure 1A).

15 Upon Cre-mediated recombination, an HA-tagged coding sequence of interest and

16 EGFP get locked into the forward orientation, allowing for robust Cre-dependent

17 expression in neurons. Conversely, in the presence of Flp the cassette is excised,

18 resulting in abolishment of CDS and EGFP reporter expression (Figure 1A). Thus, the

19 CDS is expressed only in the presence of Cre AND NOT FIpO (Table 1).

20 For proof of concept, we first generated a plasmid carrying only EGFP in the

21 reversible cassette of the CreOn-FlpOff system. The CreOn-FlpOff-EGFP plasmid was

22 co-transfected with Cre recombinase, FlpO recombinase, or both Cre and FlpO in a 
Neuronal expression by Boolean Exclusion

1 neuroblastoma-derived cell line, Neuro2A (Figure 1B, left). A plasmid driving mCherry

2 under a constitutive promoter was co-transfected as transfection control. Upon

3 transfection of the CreOn-FlpOff-EGFP plasmid alone, no EGFP expression is found in

4 any cells. As expected, when CreOn-FlpOff-EGFP plasmid is co-transfected with Cre,

5 the EGFP cassette is inverted to the correct orientation and $93.9 \% \pm 0.3$ of transfected

6 cells express EGFP (Figure 1B). When CreOn-FlpOff-EGFP plasmid was co-transfected

7 with Flp, or co-transfected with Cre and Flp, no cells expressed EGFP, suggesting that

8 Flp can efficiently turn off reporter expression (Figure 1B). This confirms that expression

9 from CreOn-FlpOff ExBoX vectors can be successfully manipulated through Boolean

10 exclusion in N2A cells.

11 Design of a complementary system that is turned ON by Flp and turned OFF by

12 Cre: FIpOn-CreOff ExBox

We next generated a complementary system that is turned on by Flp and off by

14 Cre, FlpOn-CreOff (Table 1). FlpOn-CreOff was designed using a similar internal logic,

15 where an expression cassette containing a CDS, an in-frame HA tag, P2A site, and

16 TdTomato reporter, are inverted with respect to the promoter. This expression cassette

17 is flanked by lox2722 sites, and a Flp controlled DIO switch (fDIO or fFLEX) (Xue et al,

18 2014) containing F14 and Frt sites (Figure 2A). In this system, Flp inverts the cassette,

19 resulting in CDS and TdTomato reporter expression, while Cre excises the cassette,

20 causing the abolishment of CDS and TdTomato reporter expression (Figure 2A). Thus

21 CDS expression should only occur when FlpO is present AND NOT Cre (Table 1). 
bioRxiv preprint doi: https://doi.org/10.1101/2020.07.28.224691; this version posted July 30, 2020. The copyright holder for this preprint (which

was not certified by peer review) is the author/funder, who has granted bioRxiv a license to display the preprint in perpetuity. It is made available under aCC-BY-NC-ND 4.0 International license.

Neuronal expression by Boolean Exclusion

As an initial proof-of-principle design, a FlpOn-CreOff vector driving simply a

TdTomato fluorescent reporter was generated. FlpOn-CreOff-TdTomato plasmid was

3 co-transfected with Cre, FlpO, or both Cre and FlpO. EGFP expressing plasmid was

4 used as transfection control. When the FlpOn-CreOff-TdTomato plasmid was co-

5 transfected with FlpO, approximately $85.8 \% \pm 5.6$ of transfected cells displayed

6 TdTomato expression (Figure 2B). When FlpOn-CreOff-TdTomato plasmid was co-

7 transfected with Cre alone, there were no TdTomato expressing cells. Finally, as

8 expected, co-transfection of the FlpOn-CreOff-TdTomato plasmid with both Cre and

9 FlpO resulted in no TdTomato reporter expression, confirming that Cre recombinase

10 can abolish expression of this constructs even in the presence of Flp (Figure 2B).

11 Therefore, expression of the construct occurs only in the presence of Flp AND NOT Cre

12 (Table 1).

13 Characterization of the ExBoX system in neurons

14 To test whether this newly developed system was able to drive expression in

15 neurons, we tested these constructs in primary cortical cultures. We used the same

16 plasmid combinations that were used in Neuro2A cells to perform ex-utero

17 electroporation prior to plating. Primary neuronal cultures were observed at 3 days in

18 vitro (DIV). Transfection of CreOn-FlpOff-EGFP plasmid alone resulted in no reporter

19 expression (Figure 3A). Notably, co-transfection of CreOn-FlpOff-EGFP plasmid with

20 Cre resulted in $100 \% \pm 0.0$ of transfected neurons expressing EGFP as expected (Figure

$213 \mathrm{~A})$. When CreOn-FlpOff-EGFP plasmid was co-transfected with FlpO or with FlpO and

22 Cre, we found no EGFP reporter expression in any transfected cells (Figure 3A). 
Neuronal expression by Boolean Exclusion

1 Similarly, transfection of FlpOn-CreOff-TdTomato plasmid alone resulted in no reporter

2 expression (Figure 3B). Co-transfection of FlpOn-CreOff-TdTomato plasmid with FlpO

3 resulted in $92.1 \% \pm 2.0$ of transfected cells expressing the TdTomato reporter, as

4 expected (Figure 3B). If FlpOn-CreOff-TdTomato plasmid is co-transfected with Cre

5 alone, or Cre and FlpO, it is expected that there will be no TdTomato expression since

6 Cre should excise the cassette. As predicted, no cells transfected in this combination

7 had any TdTomato expression (Figure 3B).

We then tested the neuronal expression of the ExBoX system in vivo. Initial

9 validation of CreOn-FlpOff was performed by in utero electroporation of CreOn-FlpOff-

10 EGFP plasmid with Cre, with $\mathrm{FlpO}$, or with Cre and FlpO into the lateral ventricle in

11 E15.5 mice, followed by visualization 48 hours later. mCherry-expressing plasmids were

12 used as electroporation controls. When the CreOn-FlpOff-EGFP plasmid was

13 electroporated alone or with FlpO, we found no EGFP expression (Figure 4A). Tissue

14 co-transfected with CreOn-FIpOff-EGFP plasmid and Cre had robust expression of the

15 EGFP reporter, resulting in labeling of $97.7 \% \pm 0.9$ of transfected cells (Figure $4 \mathrm{~A}$ ). Co-

16 electroporation of CreOn-FlpOff-EGFP plasmid with Cre and FlpO resulted in negligible

17 EGFP expression $(1.7 \% \pm 0.9$ of transfected cells, Figure $4 \mathrm{~A})$.

To validate FlpOn-CreOff, we electroporated the FlpOn-CreOff-TdTomato

19 plasmid alone and this resulted in no TdTomato expression. A plasmid driving EGFP

20 under the PCAG promoter was used as electroporation control. Co-electroporation of

21 FlpOn-CreOff-TdTomato plasmid with FlpO resulted in inversion of the cassette and

22 detectable expression of TdTomato in $86.9 \% \pm 3.1$ of transfected cells (Figure 4B). Co- 
Neuronal expression by Boolean Exclusion

1 electroporation of FlpOn-CreOff-TdTomato plasmid with Cre showed no TdTomato

2 expression (Figure 4B). Finally, no TdTomato expression was detected when the

3 FlpOn-CreOff-TdTomato plasmid was co-electroporated with FlpO and Cre, indicating

4 successful AND NOT exclusion (Figure 4B). These data suggest that FlpOn-CreOff and

5 CreOn-FlpOff ExBoX work efficiently in neurons, in vitro and in vivo.

6 Validation of ExBoX AAVs in vivo

To generate tools that would be useful for manipulation of gene expression in the

8 postnatal brain, we packaged the FlpOn-CreOff construct into AAV9. To validate that expression of the FlpOn-CreOff constructs is maintained in the virally-packaged form,

10 we performed stereotactic injections to deliver FlpOn-CreOff-TdTomato AAV into the

11 dentate gyrus (DG) of adult mice in vivo. FlpOn-CreOff-TdTomato AAV was co-injected

12 with either AAV-EF1 $\alpha-F I p O-W P R E(A A V-E F 1 \alpha-F I p O)$, or with AAV-EF1 $\alpha-F l p O$ and

13 pENN.AAV.CamKII 0.4. Cre. SV40 (AAV-CamkII-Cre), and expression was observed

14 after 3 weeks (Figure 5). AAV expressing EGFP was co injected in WT and when Cre

15 was injected to visualize the injection site. Similar to our previous findings with FlpOn-

16 CreOff plasmids, robust TdTomato reporter expression was observed in DG neurons

17 co-infected with AAV-FIpOn-CreOff-TdTomato and AAV-EF1 $\alpha-F l p O$ (Figure 5A, C),

18 verifying that expression of the construct in the presence of the 'ON' recombinase was

19 maintained in viral form. Furthermore, AAV-FIpOn-CreOff-TdTomato reporter

20 expression was inactivated by Camkll-Cre even in the presence of AAV-EF1 $\alpha-F l p O$

21 (Figure 5B, D; Figure S1). Thus, the FlpOn-CreOff construct works as expected when

22 packaged into AAV9. 
bioRxiv preprint doi: https://doi.org/10.1101/2020.07.28.224691; this version posted July 30, 2020. The copyright holder for this preprint (which

was not certified by peer review) is the author/funder, who has granted bioRxiv a license to display the preprint in perpetuity. It is made available under aCC-BY-NC-ND 4.0 International license.

Neuronal expression by Boolean Exclusion

We next packaged the complementary CreOn-FlpOff construct into AAV9. To

3 validate that expression of the CreOn-FlpOff construct is maintained in the virally-

4 packaged form, we performed stereotactic injections to deliver CreOn-FlpOff-EGFP

5 AAV into the dentate gyrus (DG) of adult mice in vivo. For validation for the viral CreOn-

6 FlpOff construct we incorporated a genetically-encoded Cre recombinase driven by a

7 transgene. The Grik4-cre mouse line was specifically chosen for providing robust Cre

8 expression in the hippocampus, including the DG (Supplemental Figure S2). AAV-

9 CreOn-FIpOff-EGFP was injected independently into Grik4-Cre mice or Cre-negative

10 littermates (WT), or co-injected with AAV-EF1 $\alpha$-FlpO into Grik4-Cre animals (Figure 6).

11 AAV9 constitutively expressing TdTomato (pAAV-CAG-TdTomato) was co-injected in

12 WT animals and with the AAV-EF1 $\alpha-F l p O$ injection to visualize the injection site. When

13 AAV-CreOn-FlpOff-EGFP was injected into WT (Cre-negative) animals, no EGFP

14 reporter expression was observed (Figure 6A, D, G). Conversely, injections into Grik4-

15 Cre positive animals demonstrated robust EGFP reporter expression (Figure 6B, E, H),

16 verifying the Cre-dependent activation of the virally-packaged construct. Furthermore, in

17 Grik4-Cre animals co-injection of AAV-EF1 $\alpha-F / p O$ resulted in inactivation of EGFP

18 reporter expression (Figure 6C, F; Supplemental Figure S1). These results suggest that

19 the virally-packaged ExBoX constructs are successful at driving gene expression

20 through the expected AND NOT Boolean operation. 
Neuronal expression by Boolean Exclusion

\section{Generation of Activity-modulating CreOn-FlpOff Viruses for Neuroscience} generated CreOn-FlpOff AAV constructs co-expressing EGFP and well-characterized

4 modulators of neuronal firing or synaptic release. To reduce activity, we generated a

5 CreOn-FlpOff virus that expresses Kir2.1 (AAV-CreOn-FlpOff-Kir2.1-EGFP), an inward-

6 rectifying $\mathrm{K}+$ channel that has been demonstrated to increase rheobase current and

7 reduce resting membrane potential of neurons when overexpressed (Xue et al, 2014).

8 In parallel, we cloned a version of Kir2.1 carrying three point mutations that render the

9 channel in a non-functional state, referred to as Kir2.1Mut (AAV-CreOn-FlpOff-

10 Kir2.1Mut-EGFP) (Xue et al, 2014), which can be used as a negative control for the

11 Kir2.1 construct. We also designed a CreOn-FlpOff virus encoding mNaChBac (AAV-

12 CreOn-FlpOff-mNaChBac-EGFP). This bacterial $\mathrm{Na}^{+}$ion channel has been

13 demonstrated to increase firing of neurons when overexpressed by reducing action

14 potential threshold and rheobase (Xue et al, 2014). To serve as negative control for

$15 \mathrm{mNaChBac}$ in neural circuit experiments, we cloned a non-conducting $\mathrm{mNaChBac}$

16 mutant referred to as mNaChBacMut into the CreOn-FlpOff vector (AAV-CreOn-FlpOff-

$17 \mathrm{mNaChBacMut-EGFP)}$ (Xue et al, 2014). Finally, we generated CreOn-FlpOff encoding

18 tetanus toxin (AAV-CreOn-FIpOff-TeTN-EGFP) to block synaptic transmission

19 (Sweeney et al, 1995).

We validated reporter expression of these five viral constructs in adult mice using

21 stereotactic injection to deliver each independently or in combination with AAV-EF1 $\alpha-$

22 FlpO into the DG of adult Grik4-Cre mice or WT (Cre-negative) littermates (Figure 7). To 
Neuronal expression by Boolean Exclusion

1 visualize the injection site pAAV-CAG-TdTomato was co-injected in WT, or when AAV-

2 EF $1 \alpha-F l p O$ was injected. As expected, injection of any of the viral constructs into Cre-

3 negative animals produced no EGFP reporter expression (Figure 7A, E, I, M, Q).

4 Conversely, each virus was able to produce robust EGFP reporter expression in DG

5 neurons when injected into Grik4-Cre positive animals (Figure 7B, F, J, N, R),

6 demonstrating expression of these viral constructs is Cre-dependent. Furthermore, in

7 Grik4-Cre mice injection of AAV-EF1 $\alpha$-FlpO prevented EGFP reporter expression

8 (Figure 7C, D, G, H, K, L, O, P, S, T; Supplemental Figure S3). Thus, despite the larger

9 cargo size, expression of these activity-modulating CreOn-FlpOff viral constructs was

10 similar to that of the CreOn-FlpOff-EGFP viral construct (Figure 6). Overall, our data

11 suggest that the ExBoX system can be used to efficiently control expression of multiple

12 genes of interest in a Cre- and Flp-dependent manner through AND NOT Boolean

13 operations.

\section{Discussion}

\section{Design of a simpler, more space-efficient Boolean exclusion expression system}

The ability to identify and characterize specific cell types and subpopulations has

17 been challenging in part because, until recently, cell targeting strategies have been

18 limited to populations defined by expression of a single marker or reporter. In order to

19 solve this issue and increase specificity of target selection, a number of intersectional

20 strategies have been developed (Atasoy et al, 2008; Fenno et al, 2014; Gradinaru et al,

21 2010; Jensen \& Dymecki, 2014; Plummer et al, 2015; Schnütgen et al, 2003). A

22 previous study described the generation of an expression system using Boolean logical 
bioRxiv preprint doi: https://doi.org/10.1101/2020.07.28.224691; this version posted July 30, 2020. The copyright holder for this preprint (which

was not certified by peer review) is the author/funder, who has granted bioRxiv a license to display the preprint in perpetuity. It is made available under aCC-BY-NC-ND 4.0 International license.

Neuronal expression by Boolean Exclusion

1 operations, all governed by a single AAV vector (Fenno et al., 2014). This system,

2 called INTERSECT, incorporated a modular intron-containing system capable of driving

3 transcription using multiple Boolean logical operations such as AND, NOT, AND NOT,

4 XOR, and NAND (Fenno et al., 2014). While extremely elegant, the design for the AND

5 NOT constructs was constrained by the fact that it followed the same internal logic as

6 the AND INTRSECT constructs. As a result of this constraint the currently existing AND

7 NOT system has a couple of shortcomings. The first limitation is that this system adds

8 two introns that make the constructs longer by 194 base-pairs. This is not a serious

9 concern when expressing from a plasmid, but it becomes relevant when dealing with

10 viruses with limited packaging capacity like AAV (Dong et al., 1996). Another concern

11 with the use of introns is that they make the design and cloning of other coding

12 sequences into these vectors more difficult and cumbersome. In this study, we

13 generated an alternative system aimed at solving these constraints. Thus, by design,

14 the ExBoX system has two clear advantages over previous systems: it provides more

15 cargo room and has a simpler design, allowing for replacement of the CDS cassette in a

16 simple cloning step.

17 The ExBoX system allows for robust expression only in the presence of the

18 respective ON switch, which can be reliably inactivated in the presence of the OFF

19 switch (Table 1). This is true for both plasmid (Figures 1-4) and viral constructs (Figures

20 5-7) as validated by a battery of in vitro and in vivo experiments in embryonic and

21 postnatal tissues. Altogether, these experiments demonstrate that the ExBoX system is

22 effective in delivering strong recombinase-dependent expression in a variety of settings. 
Neuronal expression by Boolean Exclusion

\section{A Boolean system to control expression with temporal and cell-type specificity} study previously inaccessible subpopulations. In situations where there is no suitable

4 specific driver for a subpopulation of interest, the ExBoX system can be used to drive

5 expression of a gene of interest or reporter in said subpopulation, provided there is a

6 recombinase driver available for a broader neuronal population, and one for the cells to

7 be excluded (Figure 8A). For example, the AND NOT logic of the ExBoX system could

8 be utilized to label or genetically manipulate $5 \mathrm{HTR}^{+} \mathrm{a}^{+}$;VIP- interneurons in the cortex

9 (Tremblay et al., 2016). This could be done by turning on expression of a CreOn-FlpOff

10 construct with HTR3a-Cre, while excluding inhibitory neurons expressing VIP-FIpO

11 (Figure 8A) (Che et al., 2018; He et al., 2017; Gerfen et al., 2013).

In addition to cell-specificity, these intersectional approaches can be used to

13 achieve temporal control. This is particularly important when studying developmental

14 events or degenerative diseases with defined critical periods. Using ExBoX one could

15 take advantage of the expression of a recombinase to provide cell-type specificity, and

16 a second recombinase to turn OFF expression at the desired time (Figure 8B). For

17 example, expression of a gene of interest in the DG can be turned ON by injecting

18 ExBoX AAVs at a desired developmental time point into Grik4-Cre mice, and later

19 turned OFF with Flp, thus creating a window of expression.

The tissue- and temporal-specificity conferred by the ExBoX system will make

21 developmental studies that were previously limited by the pre-existing tools possible.

22 With this in mind, we generated ExBoX vectors encoding for neuronal activity and 
Neuronal expression by Boolean Exclusion

1 synaptic transmission modulators, which will allow for tight control of these functional

2 manipulations in time and space. These activity-modulating tools, although well

3 characterized in a variety of circuits (see Bando et al., 2016; Burrone et al., 2002; Johns

4 et al., 1999; Lin et al., 2010; Okada and Matsuda, 2008; Priya et al., 2018; Sim and

5 Antolin et al., 2013; Sweeney et al, 1995; Xue et al, 2014 for examples), will need to be

6 validated in each particular setting and/or system. To facilitate studies where the timing

7 of CDS expression is critical, we are currently generating AAV vectors driving

8 expression of a tamoxifen-dependent FlpO (data not shown) (Goodrich et al, 2018).

9 This AAV-FIpOERT2 could be delivered at the same time as the ExBoX AAVs and used

10 to turn OFF expression by orally providing tamoxifen at a later timepoint.

\section{Expanding the toolkit to study gene function}

12 Due to the ExBoX's simple design, the system can be easily modified to

13 incorporate alternative and/or additional recombinase systems. For example, inclusion

14 of the Dre-Rox recombinase system, in addition to Cre-lox and Flp-frt, would provide

15 even greater intersectional specificity (Plummer et al, 2015). In addition to Dre-ON and

16 OFF intersectional AND NOT systems, this could theoretically enable AND-NOT-NOT

17 Boolean logic operations, permitting an even greater expanse of possibilities. In

18 addition, by using other promoters in the AAV constructs this system can be used to

19 drive expression in any cell-type or organ of interest. The broad applicability and

20 exquisite specificity of the system would make the use of these vectors particularly

21 useful for gene therapy applications. 
bioRxiv preprint doi: https://doi.org/10.1101/2020.07.28.224691; this version posted July 30, 2020. The copyright holder for this preprint (which

was not certified by peer review) is the author/funder, who has granted bioRxiv a license to display the preprint in perpetuity. It is made available under aCC-BY-NC-ND 4.0 International license.

Neuronal expression by Boolean Exclusion

In summary, we designed and generated a new set of viral tools to drive expression using Boolean exclusion logic, ExBoX. ExBoX AAVs allow for tight spatial and temporal

3 control of transcription. These new tools are simple and can be easily modified to express

4 any desired gene of interest. Our design also increases the space available for other

5 coding sequences of interest, even if this increase in capacity is somewhat small (194

6 bps). As proof of concept, we generated a variety of vectors encoding for neuronal activity

7 and synaptic transmission regulators that will be readily available to the neuroscience

8 community. Based on its simplicity, we believe the ExBoX system will help universalize

9 the use of combinatorial expression approaches. Combining these newly developed tools

10 with genetically encoded Cre and FlpO lines, in addition to a growing variety of viral tools,

11 will allow for cell-specific gene expression in a variety of systems.

\section{Materials and Methods}

13 Animals. The ICR mouse strain was purchased from Taconic. The Grik-4-Cre

14 transgenic mouse strain was purchased from The Jackson Laboratory. Generation of

15 the Grik4-cre transgenic mouse line has been described previously (Nakazawa et al.,

16 2002). Mice were housed in a controlled environment maintained at approximately $22^{*} \mathrm{C}$

17 on a 12-hour light/dark cycle. Mouse chow and water were provided ad libitum. The day

18 of vaginal plug observation was designated as embryonic day 0.5 (E0.5), and the day of

19 birth as postnatal day 0 (P0). All animal procedures presented were performed

20 according to the University of California Riverside's Institutional Animal Care and Use

21 Committee (IACUC) guidelines and approved by UC Riverside IACUC.

22 Viral constructs. The CreOn-FlpOff and FlpOn-CreOff ExBoX viral constructs were 
Neuronal expression by Boolean Exclusion

1 designed using ApE (https://jorgensen.biology.utah.edu/wayned/ape/) and Vector

2 Builder (vectorbuilder.com) free software. The plasmids were synthesized and

3 assembled by Vector Builder. Plasmid DNA was purified using the Qiagen Maxi Prep kit

4 (Qiagen Cat\#10023). AAVs were also packaged by Vector Builder into AAV2/9.

5 pENN.AAV.CamKII 0.4. Cre. SV40 (AAV5) (Addgene viral prep \#105558-AAV5;

6 http://n2t.net/addgene:105558; RRID:Addgene_105558), pAAV-CAG-TdTomato (AAV5)

7 (Addgene viral prep\#59462-AAV5; http://n2t.net/addgene:59462;

8 RRID:Addgene_59462) and pCAG-FLEX-EGFP-WPRE (AAV9) (Addgene viral prep

9 \#51502-AAV9; http://n2t.net/addgene:51502; RRID:Addgene_51502) were obtained

10 from Addgene (Oh, S.W., Harris, J.A., Ng, L., et al., 2014). rAAV5/AAV-EF1 $\alpha-F l p O-$

11 WPRE and rAAV9/CAG-GFP were obtained from the UNC GTC Vector Core.

12 In utero electroporation. Pregnant ICR mice at E15.5 were anesthetized with

13 isoflurane and an abdominal incision was made to expose the uterus. Pups were

14 visualized through the uterine wall. Plasmids diluted in fast green and phosphate

15 buffered saline (PBS) $(3 \mu \mathrm{g} / \mu \mathrm{l})$ were injected through sharpened glass capillary needles

16 into the lateral ventricle. $5 \mathrm{~mm}$ paddles were used to deliver five $40 \mathrm{~V}$ pulses of $50 \mathrm{~ms}$

17 each with 950ms intervals across the hemispheres. Uterine horns were repositioned

18 inside the female and the abdominal cavity was filled with $5 x$ penicillin/streptomycin

19 (pen/strep) in sterile PBS. Pups were collected at E17.5 via transcardial perfusion with

20 PBS and 4\% paraformaldehyde (PFA) and fixed in 4\% PFA for four hours at $4{ }^{\circ} \mathrm{C}$, rinsed

21 with PBS, and sectioned coronally at 150um on a vibrating microtome (VT100S; Leica).

22 Immunohistochemistry was performed as described (Polleux \& Ghosh, 2002). Nuclei 
Neuronal expression by Boolean Exclusion

1 were visualized with DAPI $(10 \mathrm{~g} / \mathrm{ml})$ and primary antibodies used were chicken anti-GFP

2 (1:500, Aves Labs Cat\# GFP-1010) and rabbit anti-dsRed (1:500, Takara Bio Cat\#

3 632475) with secondary antibodies goat anti-chicken 488 (1:1000, Thermo Fisher

4 Scientific Cat\# A-11039) and goat anti-rabbit 546 (1:1000, Abcam Cat\# ab60317).

5 Sections were mounted on glass microscope slides with Fluoro Gel (Electron

6 Microscopy Sciences Cat\# 1798502) and imaged with a laser-scanning confocal

7 microscope (Leica SPEII).

8 Ex utero electroporation. Ex utero electroporation was performed similarly as in utero

9 electroporation. Pregnant ICR mice at E14.5 were cervically dislocated, uterine horns

10 were removed, and pups were dissected out in Complete HBSS on ice. Plasmids were

11 injected bilaterally and $5 \mathrm{~mm}$ paddles were used to deliver five $40 \mathrm{~V}$ pulses of $50 \mathrm{~ms}$ each

12 with 950 ms intervals across each hemisphere. After electroporation, cortices were

13 removed for primary cortical culture.

14 Primary Cortical Neuron Culture. Primary cortical neurons were isolated from E14.5

15 ICR mouse embryos as described (Kim \& Magrané, 2011) using growth media as

16 described (Polleux and Ghosh 2010). 12mm circular coverslips were treated with $12 \mathrm{M}$

17 HCL overnight and thoroughly neutralized with deionized water. Acid-treated coverslips

18 were stored in a glass petri dish with $70 \%$ to $100 \%$ Ethanol. The coverslips were fire-

19 sterilized prior to use and coated with laminin and poly-D-lysine $(8.3 \mathrm{ug} / \mathrm{mL})$ in sterile

20 water in a 24-well sterile culture plate. Ex utero electroporation was performed prior to

21 dissection in Complete Hanks Balanced Salt Solution (HBSS, 2.5mM HEPES pH7.4,

22 2.5mM D-glucose, $1 \mathrm{mM} \mathrm{CaCl}_{2}, 1 \mathrm{mM} \mathrm{MgSO}_{4}, 2.5 \mathrm{mM} \mathrm{NaHCO}_{3}$ ). Neurons were plated at 
Neuronal expression by Boolean Exclusion

1 a density of $2.6 \times 10^{5} \mathrm{cell} / \mathrm{s} / \mathrm{cm}^{2}$ and maintained in Complete Neurobasal (Neurobasal

2 media, pen/strep, Glutamax, B27) in $5 \% \mathrm{CO}_{2}$ at $37^{\circ} \mathrm{C} .50 \%$ of the media was

3 exchanged with fresh media 48 hours after plating. Neurons were collected after 72

4 hours and fixed in 4\% PFA for 5 minutes, then rinsed with PBS $3 x$ for 5 min. Cells were

5 incubated in blocking buffer (PBS, $1 \%$ goat or donkey serum, $0.1 \%$ Triton-X) for 30

6 minutes at RT, rinsed with PBS 1x, then incubated in primary antibodies (chicken anti-

7 GFP (1:1000, Aves Labs Cat\# GFP-1010) and/or rabbit anti-dsRed (1:1000, Takara Bio

8 Cat\# 632475) in antibody dilution buffer (PBS, $0.1 \%$ goat or donkey serum) at $4^{\circ} \mathrm{C}$

9 overnight. The following day cells were rinsed in PBS $4 x$ for $5 \mathrm{~min}$, and were incubated

10 in secondary antibodies (goat anti-chicken 488 (1:1000, Thermo Fisher Scientific Cat\#

11 A-11039) and goat anti-rabbit 546 (1:1000, Abcam Cat\# ab60317)) and DAPI (1ug/mL)

12 in antibody dilution buffer for 2 hours, then rinsed with PBS 4x for 10min. Coverslips

13 were mounted on glass slides with Fluoro Gel and imaged with a confocal microscope.

14 Neuro2A Cell Culture. Neuro2A (N2A) cells from ATCC were maintained in DMEM

15 with pen/strep and $10 \%$ fetal bovine serum and incubated in $5 \% \mathrm{CO}_{2}$ at $37^{\circ} \mathrm{C}$. Cells

16 were plated on laminin and poly-D-lysine $(8.3 \mu \mathrm{g} / \mathrm{ml})$ coated $12 \mathrm{~mm}$ coverslips in a $24-$

17 well plate at $7.8 \times 10^{4} \mathrm{cells} / \mathrm{cm}^{2}$. Cells were transfected 24 hours later with Metafectene

18 PRO (Biontex Cat\# T040-1.0) according to manufacturer's suggested protocol with a

19 1:4 DNA to Metafectene ratio. Cells were fixed 48 hours after transfection with 4\% PFA

20 for $5 \mathrm{~min}$, rinsed with PBS, stained with DAPI $(1 \mu \mathrm{m} / \mathrm{mL})$ for one hour, then rinsed again

21 with PBS $3 x$ for $5 \mathrm{~min}$. Coverslips were mounted with Fluoro Gel onto a glass slide and

22 examined with confocal microscopy. 
Neuronal expression by Boolean Exclusion

1 Stereotaxic Injections. Stereotaxic injections were performed as described previously

2 (Osten et al., 2007) in P30 mice. Mice were put under anesthesia for the duration of the

3 procedure using isoflurane. Injections for AAV-FlpOn-CreOff-TdTomato expression

4 experiments were performed in CD1 mice targeting the DG of the Hippocampus

5 (coordinates: A/P $-1.70 \mathrm{~mm} ; \mathrm{M} / \mathrm{L} \pm 1.90 \mathrm{~mm}$; D/V, $-1.70 \mathrm{~mm}$ ). Right hemisphere

6 injections received a 400nl viral cocktail of AAV-FIpOn-CreOff-TdTomato (6.55×1012

7 GC/mL), rAAV5/EF1 $\alpha-F I p O-W P R E$, pENN.AAV.CamKII 0.4. Cre. SV40, and pCAG-

8 FLEX-EGFP-WPRE in a 1:1:1:1 ratio, whereas the contralateral hemisphere received a

$9200 \mathrm{nl}$ viral cocktail containing FlpOn-CreOff-TdTomato (6.55×1012 GC/mL), EF1 $\alpha$-FlpO-

10 WPRE, in a 1:1 ratio. Titers for commercially available AAVs were as follows:

11 pENN.AAV.CamKII 0.4. Cre. SV40 $\left(2.4 \times 10^{13} \mathrm{GC} / \mathrm{ml}\right)$, pCAG-FLEX-EGFP-WPRE $(3.3 \times$

$\left.1210^{13} \mathrm{GC} / \mathrm{ml}\right)$, pAAV-CAG-TdTomato $\left(1.2 \times 10^{13} \mathrm{GC} / \mathrm{ml}\right)$, rAAV5/EF1 $\alpha$-FlpO-WPRE (2.6

$\left.13 \times 10^{12} \mathrm{GC} / \mathrm{ml}\right)$, and rAAV9/CAG-GFP $\left(2 \times 10^{12} \mathrm{GC} / \mathrm{ml}\right)$. FlpO-negative controls were

14 injected with a viral cocktail of FlpOn-CreOff-TdTomato and pAAV-CAG-GFP. For viral

15 CreOn-FlpOff-EGFP construct experiments, injections were performed in Grik4-Cre

16 mice. Right hemisphere injections received 200nl of desired CreOn-FlpOff construct,

17 whereas the contralateral left hemisphere received a 500nl viral cocktail containing the

18 construct, rAAV5/EF1 $\alpha-F I p O-W P R E$, and pAAV-CAG-TdTomato in a 2:2:1 ratio

19 (respectively). Viral CreOn-FlpOff-EGFP constructs co-expressing following GOls were

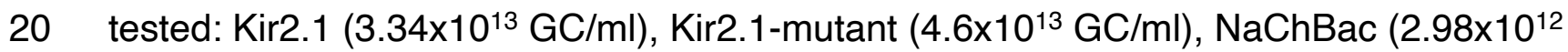

$21 \mathrm{GC} / \mathrm{ml})$, NaChBac-mutant $\left(4.93 \times 10^{13} \mathrm{GC} / \mathrm{ml}\right)$, and TeTN $\left(2.52 \times 10^{12} \mathrm{GC} / \mathrm{ml}\right)$. Three

22 weeks after injections, mice were perfused and fixed with $4 \%$ paraformaldehyde O/N at 
Neuronal expression by Boolean Exclusion

$14{ }^{\circ} \mathrm{C}$, rinsed in PBS $\times 1$, and sectioned coronally on a vibratome $(150 \mu \mathrm{m})$. Sections

2 were incubated in 4',6-diamidino-2-phenylindole (DAPI) and mounted onto slides with

3 Fluoro Gel fluorescence mounting medium (Electron Microscopy Sciences Cat\#

4 1798502). Expression was observed via confocal microscopy.

5 Image analysis. N2A and primary cortical neuron image analysis was performed with

6 FIJI (Schindelin et al., 2012). GFP+ and RFP+ cells were all manually counted. DAPI

7 counts were obtained by thresholding the DAPI channel, image was made binary, then

8 the watershed function was used and finally the analyze particles function to count

9 nuclei with a size between 20-2000 pixels ${ }^{2}$ and 0.2-1.0 circularity. Transfection

10 efficiency was calculated as $\frac{\# R F P \text { or } \# G F P}{\# D A P I} \times 100$. Percentage of transfected cells in which

11 recombinase activity resulted in fluorescent reporter (RFP or GFP) expression were

12 calculated as $\frac{\# G F P \text { or } R F P}{\# \text { transfected }} \times 100$. Images obtained from in utero electroporations were

13 counted manually, avoiding the ventricular zone where it became impossible to

14 distinguish individual cells. Percentage of ON cells were calculated the same as in N2A

15 and primary cortical neurons. The N2A, primary cortical culture, and intrauterine

16 electroporation datasets were tested for normality with the Shapiro-Wilk test and QQ

17 plot. A One-way ANOVA with Tukey's multiple comparisons test was done for N2A

18 transfection and intrauterine electroporation data (Figures 1,2,4). Unpaired t-test was

19 performed on viral injection data (Figures S1 and S3). The data set for primary cortical

20 cell counts failed to meet normality and thus Fisher's exact test was performed (Figure

21 3). Image analysis for viral constructs was performed with ImageJ. A region of interest

22 in granule cell layer of the DG and defined by the site of injection was selected. Mean 
Neuronal expression by Boolean Exclusion

1 pixel intensity of the viral reporter fluorophore in the ROI was measured. An uninjected

2 region of the hippocampus was simultaneously selected and measured for fluorescence

3 intensity, and defined as background fluorescence. Background fluorescence was then

4 subtracted from the mean pixel intensity of the ROI. The percentage of viral reporter

5 expression maintained when the OFF recombinase was co-injected was calculated as

$6 \frac{\text { mean pixel intensity } O F F}{\text { mean pixel intensity } O N} \times 100$ for each animal, and was averaged across samples $(n=3)$ for

7 each viral construct.

\section{Acknowledgements}

10 We would like to thank Drs. Edward Zagha and Kevin Wright for critically reading the

11 manuscript and providing helpful comments. We would like to thank the University of

12 North Carolina Chapel Hill Gene Therapy Center Vector Core for packaging of viral

13 constructs. pENN.AAV.CamKII 0.4.Cre.SV40 was a gift from James M. Wilson, pCAG-

14 FLEX-EGFP-WPRE was a gift from Hongkui Zeng, and pAAV-CAG-TdTomato and

15 pAAV-CAG-GFP were a gift from Edward Boyden. AAV-EF1 $\alpha$-FlpO-WPRE was a gift

16 from Karl Deisseroth.

\section{Competing interests}

19 The authors declare no competing financial interests. 
bioRxiv preprint doi: https://doi.org/10.1101/2020.07.28.224691; this version posted July 30, 2020. The copyright holder for this preprint (which

was not certified by peer review) is the author/funder, who has granted bioRxiv a license to display the preprint in perpetuity. It is made available under aCC-BY-NC-ND 4.0 International license.

Neuronal expression by Boolean Exclusion

1 Funding sources

2 This work was supported by grants from the National Institutes of Health

3 (R21MH118640 and R01NS104026 to M.M.R.; R01NS069861 and R01NS097750 to

$4 \quad$ V.S) and a Hellman Foundation Fellowship to M.M.R. 
Neuronal expression by Boolean Exclusion

1 References

2 (Bolded names = Co-first authorship)

3 Antón-bolaños, N., Sempere-ferràndez, A., Guillamón-Vivancos, T., Martini, F. J., 4 Pérez-Saiz, L., Gezelius, H., Filipehuk, A., Valdeolmillos, M., López-Bendito, G. (2019). 5 Prenatal activity from thalamic neurons governs the emergence of functional cortical 6 maps in mice. Science, 364(6444), 987-990. https://doi.org/10.1126/science.aav7617

7 Atasoy, D., Aponte, Y., Su, H. H., \& Sternson, S. M. (2008). A FLEX Switch Targets

8 Channelrhodopsin-2 to Multiple Cell Types for Imaging and Long-Range Circuit

9 Mapping. Journal of Neuroscience, 28(28), 7025-7030.

10 https://doi.org/10.1523/JNEUROSCI.1954-08.2008

11 Awatramani, R., Soriano, P., Rodriguez, C., Mai, J. J., \& Dymecki, S. M. (2003). Cryptic 12 boundaries in roof plate and choroid plexus identified by intersectional gene activation,

13 Nat. Genet., 35(1), 70-75. https://doi.org/10.1038/ng1228

14 Bando, Y., Irie, K., Shimomura, T., Umeshima, H., Kushida, Y., Kengaku, M., Fujiyoshi, 15 Y., Hirano, T., Tagawa, Y. (2016). Control of Spontaneous Ca2+ Transients Is Critical 16 for Neuronal Maturation in the Developing Neocortex. Cerebral Cortex, 26(1), 106-117. 17 https://doi.org/10.1093/cercor/bhu180

18 Branda, C. S., \& Dymecki, S. M. (2004). Talking about a Revolution: The Impact of Site19 Specific Recombinases on Genetic Analyses in Mice. Developmental Cell, 6, 7-28.

20 Burrone, J., O’Byrne, M., \& Murthy, V. N. (2002). Multiple forms of synaptic plasticity 21 triggered by selective suppression of activity in individual neurons. Nature, 420(6914), 22 414-418. https://doi.org/10.1038/nature01242

23 Capecchi, M. (1989). Altering the genome by homologous recombination. Science, 24 244(4910), 1288-1292. https://doi.org/10.1126/science.2660260

25 Che, A., Babij, R., lannone, A. F., Fetcho, R. N., Ferrer, M., Liston, C., Fishell, G., De 26 Marco Garcia, N. V. (2018). Layer I interneurons sharpen sensory maps during neonatal 27 development. Neuron, 99(1), 98-116.

28 https://doi.org/10.1016/j.neuron.2018.06.002.Layer

29 Daigle, T. L., Madisen, L., Hage, T. A., Valley, M. T., Knoblich, U., Larsen, R. S., ... Li,

30 L. (2019). A suite of transgenic driver and reporter mouse lines with enhanced brain cell 31 type targeting and functionality. Cell, 174(2), 465-480.

32 https://doi.org/10.1016/j.cell.2018.06.035.A

33 Darmanis, S., Sloan, S. A., Zhang, Y., Enge, M., Caneda, C., Shuer, L. M., Hayden

34 Gephart, M. G., Barres, B. A., \& Quake, S. R. (2015). A survey of human brain

35 transcriptome diversity at the single cell level. Proceedings of the National Academy of

36 Sciences, 112(23), 7285-7290. https://doi.org/10.1073/pnas.1507125112 
1 Dong, J., Fan, P., \& Frizzell, R. A. (1996). Quantitative analysis of Packaging Capacity

2 of Recombinant Adeno-Associated Virus. Human Gene Therapy, 7, 2101-2112.

3 Dymecki, S. M., Ray, R. S., \& Kim, J. C. (2010). Mapping Cell Fate and Function Using

4 Recombinase-Based Intersectional Strategies. Guide to Techniques in Mouse

5 Development, Part B: Mouse Molecular Genetics. Methods Enzymol. (2nd ed., Vol.

6 477). https://doi.org/10.1016/S0076-6879(10)77011-7

7 Fenno, L. E., Mattis, J., Ramakrishnan, C., Hyun, M., Lee, S. Y., He, Tucciarone, J., 8 Selimbeyoglu, A., Berndt, A., Grosenick, L., Zalocusky, K.A., Bernstein, H., Swanson, 9 H., Perry, C., Diester, I., Boyce, F.M., Bass, C., Neve, R., Huang, Z.J., \& Deisseroth, K. 10 (2014). Targeting cells with single vectors using multiple-feature Boolean logic. Nature 11 Methods, 11, 763-772. https://doi.org/10.1038/nmeth.2996

12 Garcia-Garcia, M. J., Eggenschwiler, J. T., Caspary, T., Alcorn, H. L., Wyler, M. R., 13 Huangfu, D., Rakeman, A.S., Lee, J.D., Feinberg, E.H., Timmer, J.R., \& Anderson, K. V. 14 (2005). Analysis of mouse embryonic patterning and morphogenesis by forward 15 genetics. PNAS, 5(7), 5913-5919. www.pnas.org/cgi/doi/10.1073/pnas.0501071102

16 Gerfen, C. R., Paletzki, R., \& Heintz, N. (2013). GENSAT BAC cre-recombinase driver 17 lines to study the functional organization of cerebral cortical and basal ganglia circuits.

18 Neuron, 80(6), 1368-1383. https://doi.org/10.1016/j.neuron.2013.10.016

19 Glover, C. P., Bienemann, A. S., Heywood, D. J., Cosgrave, A. S., \& Uney, J. B. (2002). 20 Adenoviral-mediated, high-level, cell-specific transgene expression: a SYN1-WPRE 21 cassette mediates increased transgene expression with no loss of neuron specificity.

22 Molecular therapy: the journal of the American Society of Gene Therapy, 5(5 Pt 1), 50923 516. https://doi.org/10.1006/mthe.2002.0588

24 Goodrich, M. M., Talhouk, R., Zhang, X., \& Goodrich, D. W. (2018). An approach for 25 controlling the timing and order of engineered mutations in mice. Genesis (New York, 26 N.Y. : 2000), 56(8), e23243. https://doi.org/10.1002/dvg.23243

27 Gordon, J., \& Ruddle, F. (1981). Integration and stable germ line transmission of genes 28 injected into mouse pronuclei. Science, 214(4526), 1244-1246.

29 https://doi.org/10.1126/science.6272397

30 Gradinaru, V., Zhang, F., Ramakrishnan, C., Mattis, J., Prakash, R., Diester, I.,

31 Goshen, I., Thompson, K. R., Deisseroth, K. (2010). Molecular and Cellular Approaches 32 for Diversifying and Extending Optogenetics. Cell, 141(1), 154-165.

33 https://doi.org/10.1016/j.cell.2010.02.037

34 Gu, H., Marth, J. D., Orban, P. C., Mosmann, H., \& Rajewsky, K. (1994). Deletion of a 35 DNA Polymerase $\beta$ Gene Segment in T Cells Using Cell Type-Specific Gene Targeting.

36 Science, 265(5168), 103-106. https://doi.org/10.1126/science.8016642 
Neuronal expression by Boolean Exclusion

1 He, M., Tucciarone, J., Lee, S., Nigro, M. J., Kim, Y., Levine, J. M., Kelly, S.M.,

2 Krugikov, I., Wu, P., Chen, Y., Gong, L., Hou, Y., Osten, P., Rudy, B., Huang, Z. J.

3 (2016). Neuron, 91(6), 1228-1243.

4 https://doi.org/10.1016/j.neuron.2016.08.021.Strategies

5 Hogan, B., \& Williams, J. (1981). Integration of foreign genes into the mammalian germ

6 line: Genetic engineering enters a new era. Nature, 294(5836), 9-10.

7 https://doi.org/10.1038/294009a0

8 Jaenisch, R., \& Mintz, B. (1974). Simian Virus 40 DNA Sequences in DNA of Healthy

9 Adult Mice Derived from Preimplantation Blastocysts Injected with Viral DNA.

10 Proceedings of the National Academy of Sciences, 71(4), 1250-1254.

11 https://doi.org/10.1073/pnas.71.4.1250

12 Jensen, P., \& Dymecki, S. M. (2014). Essentials of Recombinase-Based Genetic Fate

13 Mapping in Mice. Methods Mol Biol, 1092, 437-454. https://doi.org/10.1007/978-1-

14 60327-292-6

15 Johns, D. C., Marx, R., Mains, R. E., O’Rourke, B., \& Marbán, E. (1999). Inducible

16 genetic suppression of neuronal excitability. Journal of Neuroscience, 19(5), 1691-

17 1697. https://doi.org/10.1523/jneurosci.19-05-01691.1999

18 Kakava-georgiadou, N., Zwartkruis, M. M., Bullich-vilarrubias, C., Adan, R. A. H., \&

19 Marti, F. (2019). An Intersectional Approach to Target Neural Circuits With Cell- and

20 Projection-Type Specificity: Validation in the Mesolimbic Dopamine System. Frontiers in

21 Molecular Neuroscience, 12(February), 1-9. https://doi.org/10.3389/fnmol.2019.00049

22 Kim H.J., Magrané J. (2011) Isolation and Culture of Neurons and Astrocytes from the

23 Mouse Brain Cortex. In: Manfredi G., Kawamata H. (eds) Neurodegeneration. Methods

24 in Molecular Biology (Methods and Protocols), vol 793. Humana Press, Totowa, NJ

25 Kozorovitskiy, Y., Saunders, A., Johnson, C. A., Lowell, B. B., Sabatini, B. L., Israel, B., 26 \& Medical, D. (2012). Recurrent network activity drives striatal synaptogenesis. Nature,

27 485(7400), 646-650. https://doi.org/10.1038/nature11052.

28 Kristianto, J., Johnson, M. G., Zastrow, R. K., Radcliff, A. B., \& Blank, R. D. (2017).

29 Spontaneous recombinase activity of Cre-ERT2 in vivo. Transgenic research, 26(3),

30 411-417. https://doi.org/10.1007/s11248-017-0018-1

31 Lin, C. W., Sim, S., Ainsworth, A., Okada, M., Kelsch, W., \& Lois, C. (2010). Genetically

32 Increased Cell-Intrinsic Excitability Enhances Neuronal Integration into Adult Brain

33 Circuits. Neuron, 65(1), 32-39. https://doi.org/10.1016/j.neuron.2009.12.001

34 Madisen, L., Garner, A. R., Carandini, M., Zeng, H., \& Cheng, A. (2015). Transgenic

35 Mice for Intersectional Targeting of Neural Sensors and Effectors with High Specificity

36 and Performance. Neuron, 85, 942-958. https://doi.org/10.1016/j.neuron.2015.02.022 
Neuronal expression by Boolean Exclusion

1 Merte, J., Wang, Q., Vander Kooi, C. W., Sarsfield, S., Leahy, D. J., Kolodkin, A. L., \&

2 Ginty, D. D. (2010). A forward genetic screen in mice identifies Sema3A ${ }^{\mathrm{K} 108 \mathrm{~N}}$, which

3 binds to Neuropilin-1 but cannot signal. Journal of Neuroscience, 30(16), 5767-5775.

4 https://doi.org/10.1523/JNEUROSCI.5061-09.2010

5 Nakazawa K; Quirk MC; Chitwood RA; Watanabe M; Yeckel MF; Sun LD; Kato A; Carr

6 CA; Johnston D; Wilson MA; Tonegawa S. (2002). Requirement for hippocampal CA3

7 NMDA receptors in associative memory recall. Science 297(5579):211-8.

8 Nusslein-Volhard, C., \& Wieschaus, E. (1980). Mutations affecting segment number and 9 polarity in Drosophila. Nature, 287(October), 795-801.

10 https://doi.org/10.1038/287795a0

11 Oh, S. W., Harris, J. A., Ng, L., Winslow, B., Cain, N., Mihalas, S., Wang, Q., Lau, C.,

12 Kuan, L., Henry, A. M., Mortrud, M. T., Ouellette, B., Nguyen, T., Sorensen, S. A.,

13 Slaughterbeck, C., Wakeman, W., Li, Y., Feng, D., ... Anh Zeng, H. (2014). A

14 mesoscale connectome of the mouse brain. Nature, 508(7495), 207-214.

15 https://doi.org/10.1038/nature13186 Okada, M., \& Matsuda, H. (2008). Chronic lentiviral

16 expression of inwardly rectifying $\mathrm{K}+$ channels (Kir2.1) reduces neuronal activity and

17 downregulates voltage-gated potassium currents in hippocampus. Neuroscience,

18 156(2), 289-297. https://doi.org/10.1016/j.neuroscience.2008.07.038

19 Osten, P., Cetin, A., Komai, S., Eliava, M., \& Seeburg, P. H. (2007). Stereotaxic gene

20 delivery in the rodent brain. Nature Protocols, 1(6), 3166-3173.

21 Plummer, N. W., Evsyukova, I. Y., Robertson, S. D., Marchena, J. De, Tucker, C. J., \&

22 Jensen, P. (2015). Expanding the power of recombinase-based labeling to uncover

23 cellular diversity. Development, 142, 4385-4393. https://doi.org/10.1242/dev.129981

24 Polleux, F., \& Ghosh, A. (2002). The Slice Overlay Assay: A Versatile Tool to Study the

25 Influence of Extracellular Signals on Neuronal Development. Science's STKE,

26 2002(136), pl9.

27 Priya, R., Paredes, M. F., Karayannis, T., Yusuf, N., Liu, X., Jaglin, X., Graef, I.,

28 Alvarez-Buylla A., Fishell, G. (2018). Activity Regulates Cell Death within Cortical

29 Interneurons through a Calcineurin-Dependent Mechanism. Cell Reports, 22(7), 1695-

30 1709. https://doi.org/10.1016/j.celrep.2018.01.007

31 Rubin, G., \& Spradling, A. (1982). Genetic transformation of Drosophila with

32 transposable element vectors. Science, 218(4570), 348-353.

$33 \mathrm{https}: / /$ doi.org/10.1126/science.6289436

34 Sauer, B., \& Mcdermott, J. (2004). DNA recombination with a heterospecific Cre

35 homolog identified from comparison of the pac-c1 regions of P1-related phages. Nucleic

36 Acids Research, 32(20), 1-10. https://doi.org/10.1093/nar/gkh941 1-10

37 doi:10.1093/nar/gkh941 
Neuronal expression by Boolean Exclusion

1 Saunders, A., Johnson, C. A., Sabatini, B. L., \& Miyamichi, K. (2012). Novel

2 recombinant adeno-associated viruses for Cre activated and inactivated transgene

3 expression in neurons. Frontiers in Neural Circuits, 6(47), 1-10.

4 https://doi.org/10.3389/fncir.2012.00047

5 Schindelin, J., Arganda-Carreras, I., Frise, E., Kaynig, V., Longair, M., Pietzsch, T.,

6 Preibisch, S., Rueden, C., Saalfeld, S., Schmid, B., Tinevez, J.-Y., White, D. J.,

7 Hartenstein, V., Eliceiri, K., Tomancak, P., \& Cardona, A. (2012). Fiji: An open-source

8 platform for biological-image analysis. Nature Methods, 9(7), 676-682.

9 Schnütgen, F., Doerflinger, N., Calléja, C., Wendling, O., Chambon, P., \& Ghyselinck,

10 N. B. (2003). A directional strategy for monitoring Cre-mediated recombination at the

11 cellular level in the mouse. Nature Biotechnology, 21, 562-565.

12 https://doi.org/10.1038/nbt811

13 Sim, S., Antolin, S., Lin, C. W., Lin, Y. X., \& Lois, C. (2013). Increased cell-intrinsic

14 excitability induces synaptic changes in new neurons in the adult dentate gyrus that

15 require Npas4. Journal of Neuroscience, 33(18), 7928-7940.

16 https://doi.org/10.1523/JNEUROSCI.1571-12.2013

17 Sternson, S. M., Atasoy, D., Betley, J. N., Henry, F. E., \& Xu, S. (2016). An Emerging

18 Technology Framework for the Neurobiology of Appetite. Cell Metabolism, 23(2), 234-

19 253. https://doi.org/10.1016/j.cmet.2015.12.002

20 Sweeney, S.T., Broadie, K., Keane, J., Niemann H., O’Kane, C.J. (1995). Targeted

21 expression of tetanus toxin light chain in Drosophila specifically eliminates synaptic

22 transmission and causes behavioral defects. Neuron 14, 341-351.

23 Tremblay, R., Lee, S., \& Rudy, B. (2016). GABAergic Interneurons in the Neocortex:

24 From Cellular Properties to Circuits. Neuron, 91(2), 260-292.

25 https://doi.org/10.1016/j.neuron.2016.06.033

26 Tsien, J. Z., Chen, D. F., Gerber, D., Tom, C., Mercer, E. H., Anderson, D. J., Mayford,

27 M., Kandel, E. R., \& Tonegawa, S. (1996). Subregion- and Cell Type-Restricted Gene

28 Knockout in Mouse Brain. Cell, 87(7), 1317-1326. https://doi.org/10.1016/S0092-

29 8674(00)81826-7

30 Wright, K. M., Lyon, K., Leung, H., Leahy, D. J., Ma, L., \& David, D. (2013).

31 Dystroglycan organizes axon guidance cue localization and axonal pathfinding. Neuron,

32 76(5), 931-944. https://doi.org/10.1016/j.neuron.2012.10.009.

33 Xue, M., Atallah, B. V., \& Scanziani, M. (2014). Equalizing excitation-inhibition ratios

34 across visual cortical neurons. Nature, 511(7511), 596-600.

35 https://doi.org/10.1038/nature13321 
bioRxiv preprint doi: https://doi.org/10.1101/2020.07.28.224691; this version posted July 30, 2020. The copyright holder for this preprint (which was not certified by peer review) is the author/funder, who has granted bioRxiv a license to display the preprint in perpetuity. It is made available under aCC-BY-NC-ND 4.0 International license.

Neuronal expression by Boolean Exclusion

1 Zhang, F., Aravanis, A.M., Adamantidis, A., Lecea, L., and Deisseroth, K. (2007).

2 Circuit-breakers: optical technologies for probing neural signals and systems. Nature

3 Reviews Neuroscience 8(August), 577-581. https://doi:10.1038/nr n2192 
Neuronal expression by Boolean Exclusion

\section{$1 \quad$ Figure Legends}

2 Table 1. Conceptual basis for the Expression by Boolean Exclusion (AND NOT)

3 system using multiple recombinases. Expression of a gene of interest (GOI) can be

4 spatially and temporally manipulated through the use of multiple recombinases. In this

5 model, expression of a GOI depends on the presence of an $\mathrm{ON}$ recombinase, and is

6 prevented by the presence of an OFF recombinase. Thus, gene expression only occurs

7 in cells where the ON recombinase is present AND NOT the OFF recombinase.

8 Controlling where and when the ON and OFF recombinases are expressed provides a

9 high level of specificity for targeting cell populations.

11 Figure 1. Design and proof of concept for CreOn-FIpOff constructs. (A) Schematic

12 representation of the CreOn-FlpOff construct. It is composed of an inverted expression

13 cassette encoding for a coding sequence (CDS) fused to an HA tag, a P2A site, and

14 EGFP, which is flanked by Frt, lox2722, and loxP sites. Presence of Cre recombinase

15 results in inversion of the cassette and expression. Presence of FlpO results in removal

16 of the cassette. (B) Expression of fluorescent reporter proteins in Neuro2A cells

17 transfected with CreOn-FlpOff-EGFP construct (green) and pCAG-mCherry (red,

18 loading control). Co-transfection with pCAG-Cre plasmid causes inversion of the

19 cassette into the "ON" position and EGFP expression. Co-transfection of pCAG-FIpO

20 deletes the cassette and abolishes EGFP expression. (B, right panel) Quantification of

21 N2A cell transfections. Upon transfection with Cre, the CreOn-FlpOff-EGFP construct

22 results in $93.9 \% \pm 0.3$ of transfected cells expressing EGFP, while co-transfection with 
Neuronal expression by Boolean Exclusion

1 FlpO results in abolishment of EGFP expression. $\mathrm{N}=3$ independent experiments, error

2 bars \pm SEM. ANOVA $p<0.001$; Tukey post-hoc test ${ }^{* \star \star} p<0.0001$ vs. all other

3 transfections. Scale bar $30 \mu \mathrm{m}$.

5 Figure 2. Design and proof of principle for FlpOn-CreOff constructs. (A) Schematic

6 representation of the FlpOn-CreOff construct. The inverted expression cassette is

7 flanked by lox2722, F14, and Frt sites. Presence of Flp recombinase results in inversion

8 of the cassette and expression. Presence of Cre results in removal of the cassette. (B)

9 Expression of fluorescent reporters in Neuro2A cells transfected with FlpOn-CreOff-

10 TdTomato construct (red) and pCAG-EGFP (green, transfection control) in Neuro2A

11 cells. Co-transfection with pCAG-FlpO causes inversion of the cassette into the "ON"

12 position and TdTomato expression. Transfection with pCAG-Cre removes the cassette

13 and abolishes TdTomato expression. Upon transfection with FlpO, the FlpOn-CreOff-

14 TdTomato construct results in detectable expression of reporter in $85.8 \% \pm 5.6$ of

15 transfected cells, while co-transfection with Cre results in abolishment of TdTomato

16 expression (right panel). $\mathrm{N}=3$ independent experiments, error bars $\pm \mathrm{SEM}$. ANOVA

$17 p<0.01$; Tukey post-hoc test ${ }^{* * *} p<0.0001$ vs. all other transfections. Scale bar $30 \mu \mathrm{m}$.

19 Figure 3. Validation of CreOn-FIpOff in primary cortical neurons. (A) Primary

20 cortical neurons transfected with CreOn-FlpOff and Cre results in $100 \% \pm 0.0$ of

21 transfected cells expressing EGFP. Without Cre or in the presence of FlpO there is no 
Neuronal expression by Boolean Exclusion

1 EGFP expression in any neurons. pCAG-mCherry was co-transfected as transfection control. (B) Primary cortical neurons transfected with FlpOn-CreOff-TdTomato and FlpO

3 results in detectable TdTomato expression in $92.1 \% \pm 2.0$ of transfected cells (right).

4 pCAG-EGFP was co-transfected as transfection control. Without FlpO, or in the

5 presence of Cre, there is no TdTomato expression in any neurons. $\mathrm{N}=3$, error bars

$6 \pm$ SEM. Fisher's exact test ${ }^{* \star *} p<0.0001$. Scale bar $30 \mu \mathrm{m}$.

Figure 4. In vivo validation of CreOn-FIpOff and FlpOn-CreOff vectors via in utero

electroporation (IUE). (A) Co-electroporation of CreOn-FlpOff-EGFP with mCherry

10 reporter, Cre + pCAG-mCherry, FlpO-mCherry, or Cre + FlpO-mCherry in e15.5 ICR

11 mouse embryos. Electroporation of CreOn-FlpOff-EGFP with Cre results in $97.7 \% \pm 0.9$

12 of transfected cells expressing EGFP (right). Electroporation with FlpO results in no

13 expression and electroporation with Cre and FlpO results in only $1.7 \% \pm 0.9$ of cells still

14 expressing EGFP. mCherry expression serves as electroporation control. (B) Co-

15 electroporation of FIpOn-CreOff-TdTomato with pCAG-IRES-EGFP reporter, Cre-IRES-

16 EGFP, FlpO, or Cre-IRES-EGFP + FlpO in e15.5 Swiss-Webster embryos. pCAG-IRES-

17 EGFP expression was used as electroporation control.Electroporation of FlpOn-CreOff-

18 TdTomato with FlpO results in $86.9 \% \pm 3.1$ of transfected cells expressing TdTomato

19 (right). Co-electroporation with Cre, or with Cre and FlpO, results in no cells expressing

20 TdTomato. $\mathrm{N}=3$, error bars \pm SEM. ANOVA $\mathrm{p}<0.001$ for both sets of experiments; Tukey

21 post-hoc test: ${ }^{\star \star \star} p<0.0001$ vs. all other transfections. Scale bar $100 \mu \mathrm{m}$. 
Neuronal expression by Boolean Exclusion

1 Figure 5. In-vivo validation of FIpOn-CreOff AAV by stereotactic injection in postnatal DG neurons. (A-I) Expression of viral FlpOn-CreOff-TdTomato construct

3 (red) in WT animals co-injected with pAAV-CAG-GFP (A, D, G), with AAV-EF1 $\alpha-F I p O-$

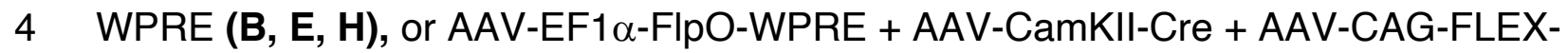
EGFP (C, F, I). EGFP expression is used to visualize the injection site in the absence of

6 TdTomato expression. Even in the presence of FlpO, Cre injection resulted in

7 inactivation of TdTomato reporter expression (C, F). DAPI (blue) was used to visualize

8 nuclei. Scale bar: $150 \mu \mathrm{m}$.

10 Figure 6. In-vivo validation of CreOn-FIpOff AAV in the dentate gyrus of postnatal

11 mice. (A-I) Expression of viral CreOn-FlpOff-EGFP construct (green) in WT animals (A,

12 D, G), in Grik4-Cre animals (B, E, H), and in Grik4-Cre mice co-injected with AAV-

13 EF1 $\alpha$-FlpO-WPRE (C, F, I). pAAV-CAG-TdTomato (red) was co-injected when

14 necessary to visualize the injection site. Even in the presence of Cre, FlpO injection

15 resulted in inactivation of reporter expression by the CreOn-FlpOff-EGFP virus (C, F).

16 EGFP labeling in the molecular layer of AAV-EF1 $\alpha-F l p O$ injected animals $(C, F)$ is from

17 axonal projections from the contralateral side. DAPI (blue) was used to visualize nuclei.

18 Scale bar: $150 \mu \mathrm{m}$.

20 Figure 7. In-vivo validation of CreOn-FIpOff AAV constructs to manipulate

21 neuronal activity. (A-T) Expression of fluorescent reporter by CreOn-FlpOff AAVs 
Neuronal expression by Boolean Exclusion

1 (green) co-expressing (A-D) Kir2.1, (E-H) Kir2.1-Mutant, (I-L) NaChBac, (M-P)

2 NaChBac-mutant, and (Q-T) TETN in WT (A, E, I, M, Q) , Grik4-Cre animals (B, F, J,

$3 \mathbf{N}, \mathbf{R})$ and Grik4-Cre animals co-injected with AAV-EF1 $\alpha$-FIpO-WPRE (C, D, G, H, K, L,

$4 \mathrm{O}, \mathrm{P}, \mathrm{S}, \mathrm{T})$. Injections delivering AAV-EF1 $\alpha-F I p O$ included pAAV-CAG-TdTomato (red)

5 in order to visualize infected cells. In the presence of Cre and FlpO, expression of the

6 CreOn-FlpOff virus was inactivated (C, D, G, H, K, L, O, P, S, T). EGFP labeling in the

7 molecular layer of TeTN/FlpO injected animals $(\mathrm{T})$ is from axonal projections from the

8 contralateral side. Scale bar: $150 \mu \mathrm{m}$.

10 Figure 8. The ExBoX system can be utilized in multiple ways. (A) Expression of a

11 gene of interest (GOI) can be restricted to a specific subpopulation of cells. Only the

12 subpopulation of cells expressing the ON recombinase, but not the OFF recombinase,

13 will express the GOI. (B) ExBoX can also be used for temporal control of expression. In

14 this scheme, activation of the ON recombinase is used just prior to a critical period of

15 interest. Introduction or activation of the OFF recombinase at the end of this critical

16 period will turn off expression of the GOI. This serves to reduce confounding factors

17 during later experimental observation, as GOI expression is no longer present. 


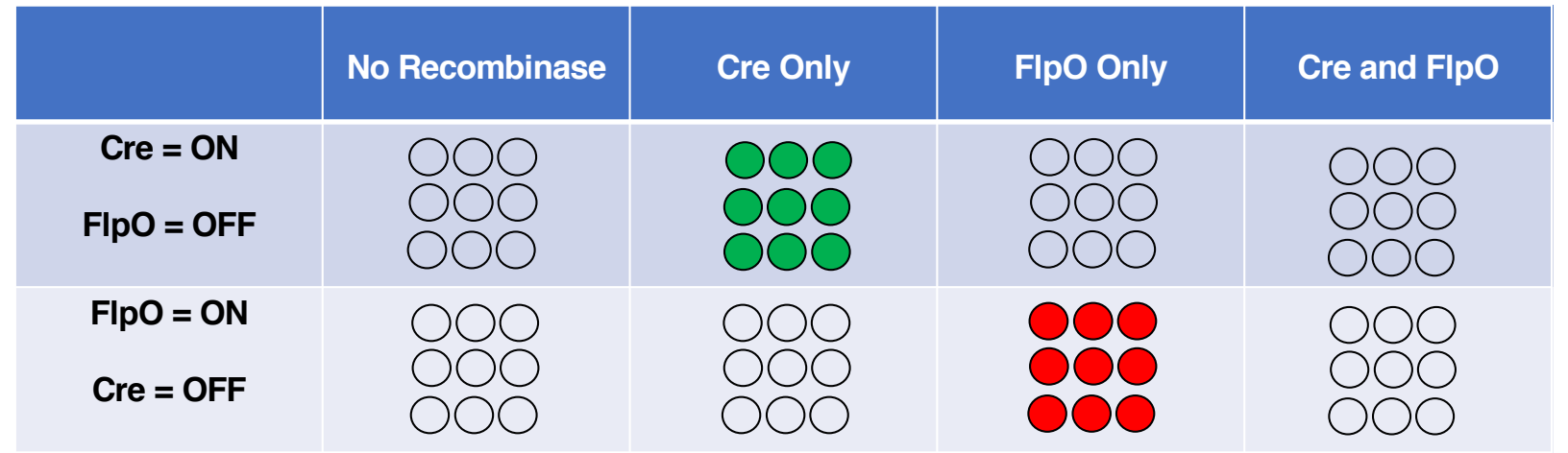

Table 1. Conceptual basis for the Expression by Boolean Exclusion (AND NOT) system using multiple recombinases. 


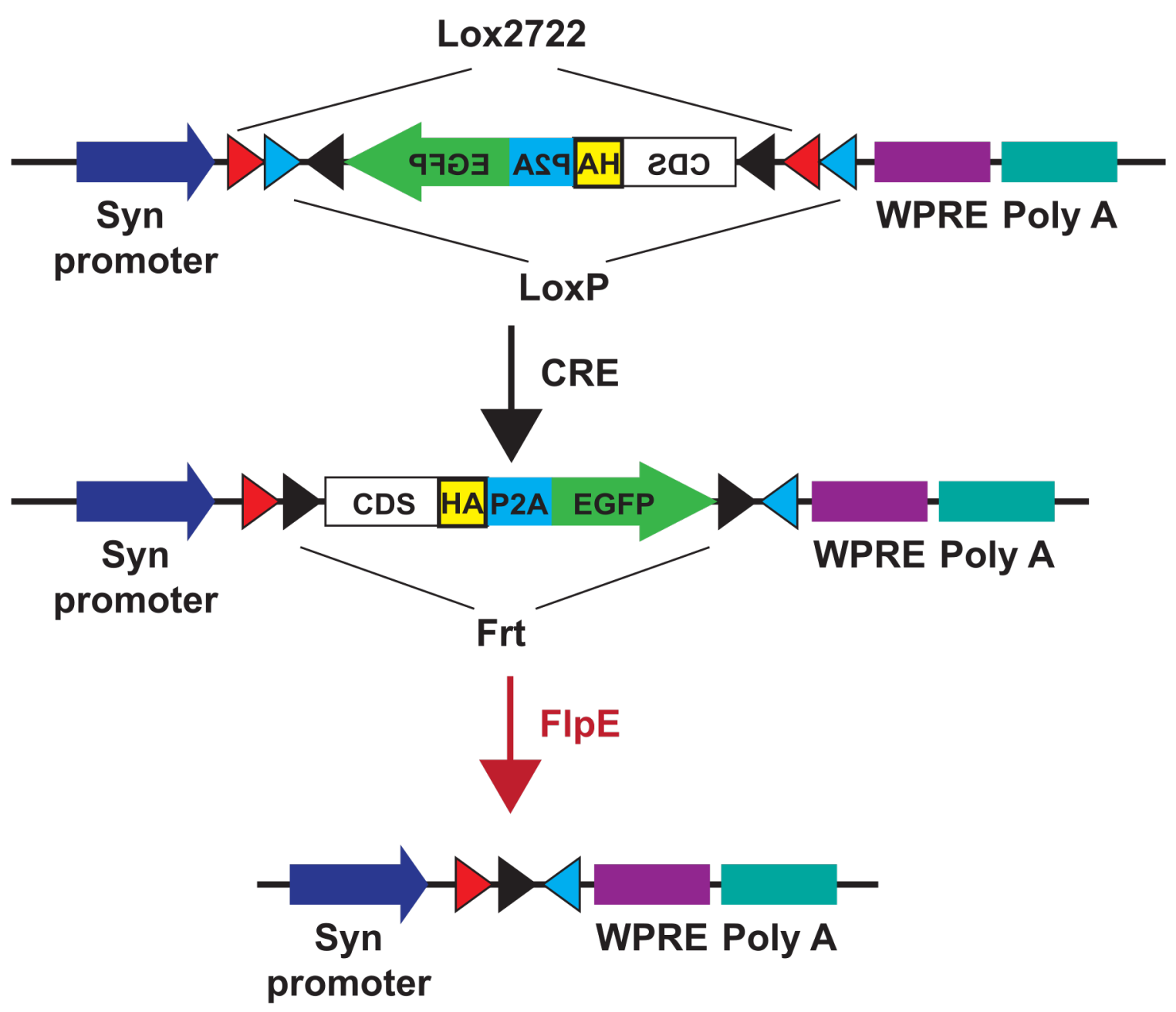

CreOn-FIpOff-EGFP

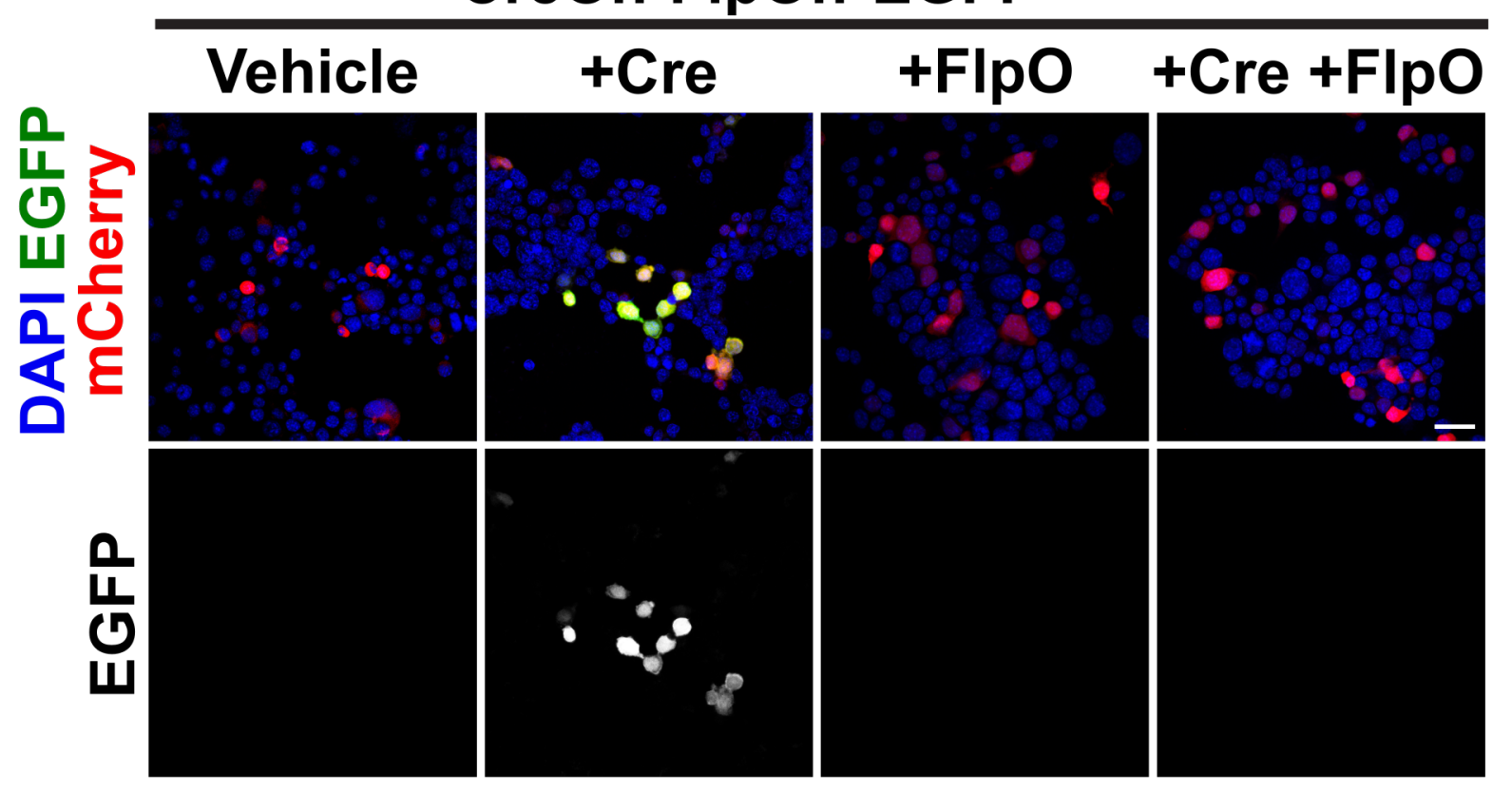

CreOn-FIpOff-EGFP

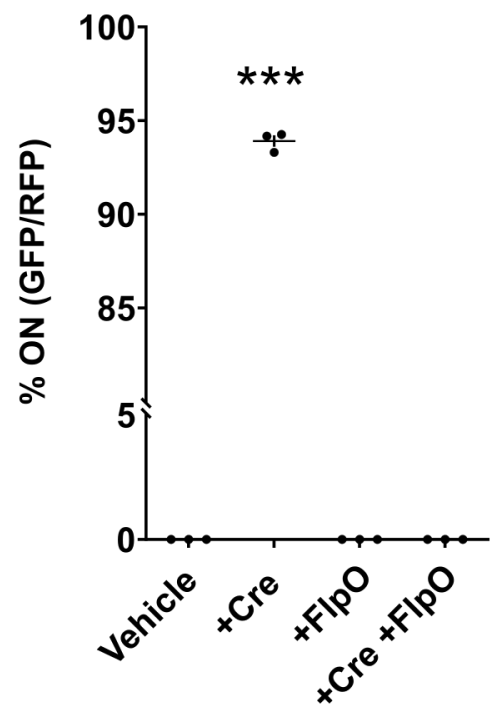

Constructs 
A
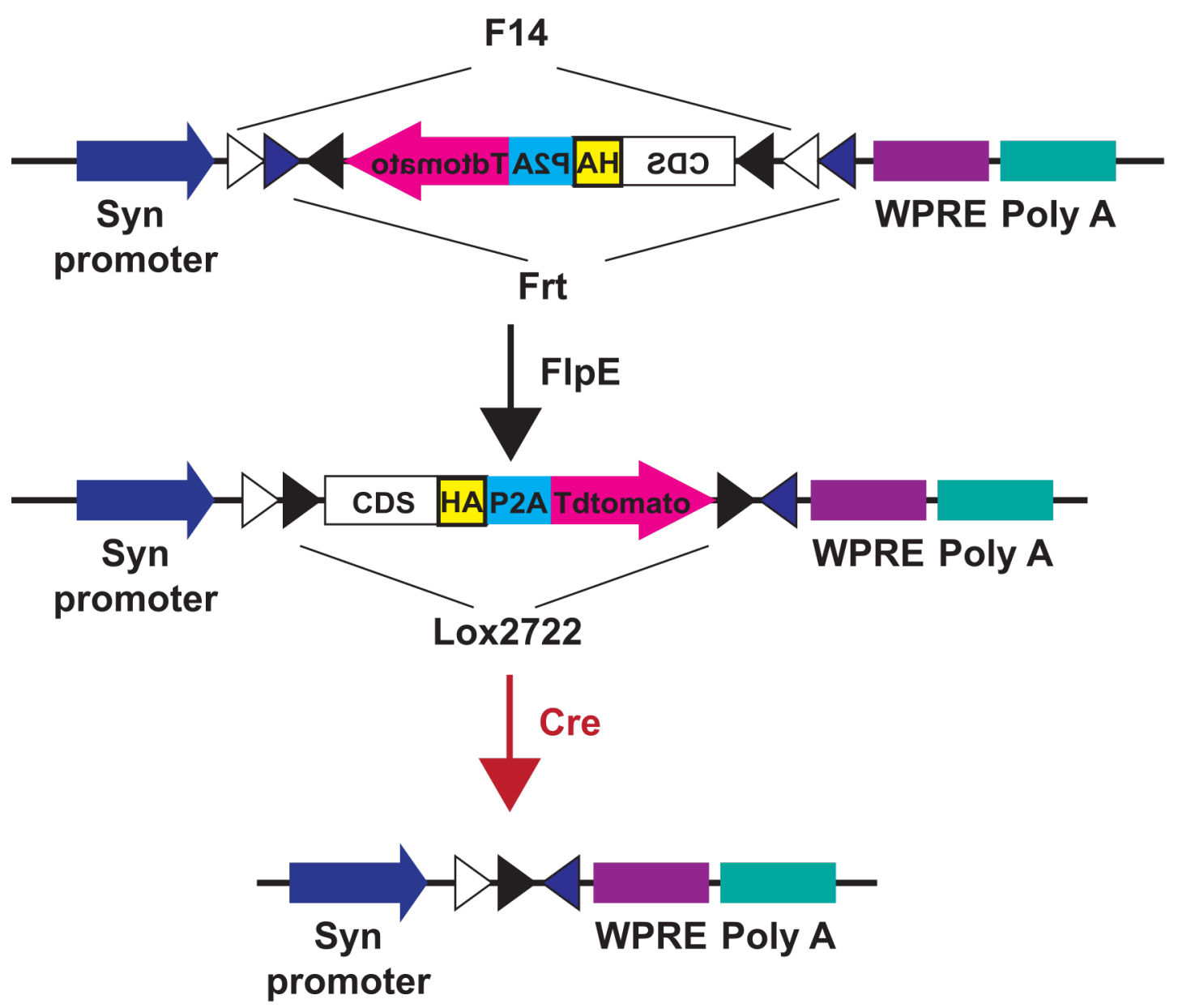

FIpOn-CreOff-TdTomato

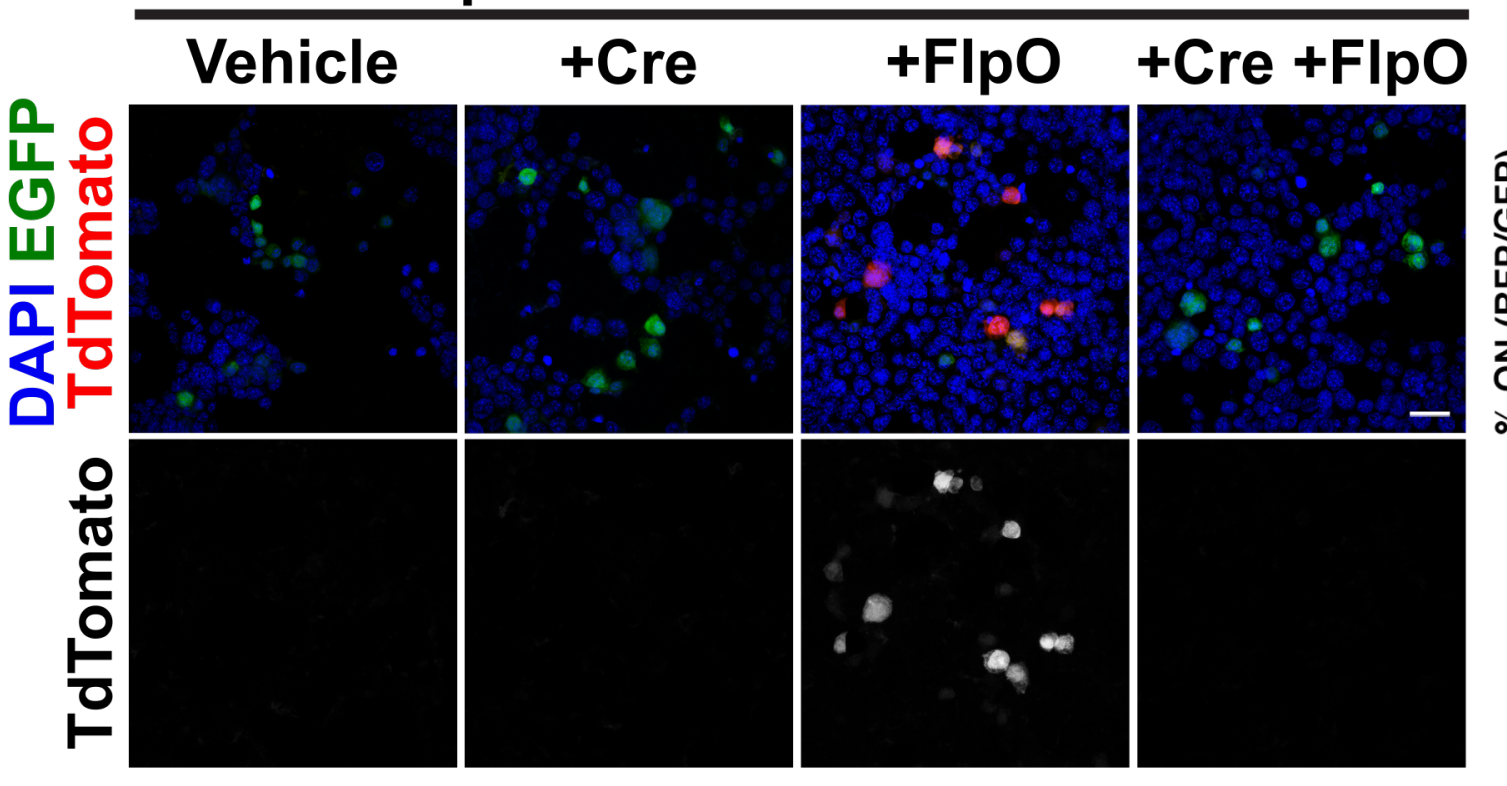

FIpOn-CreOff-TdTomato

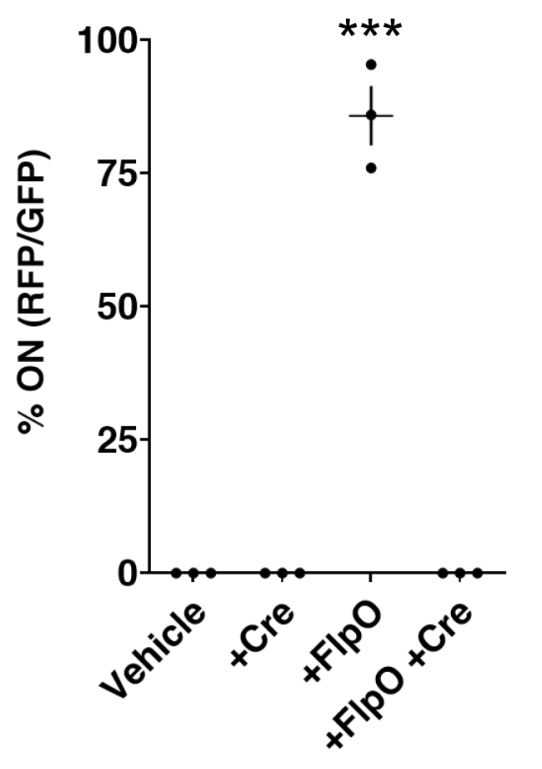

Constructs 
A

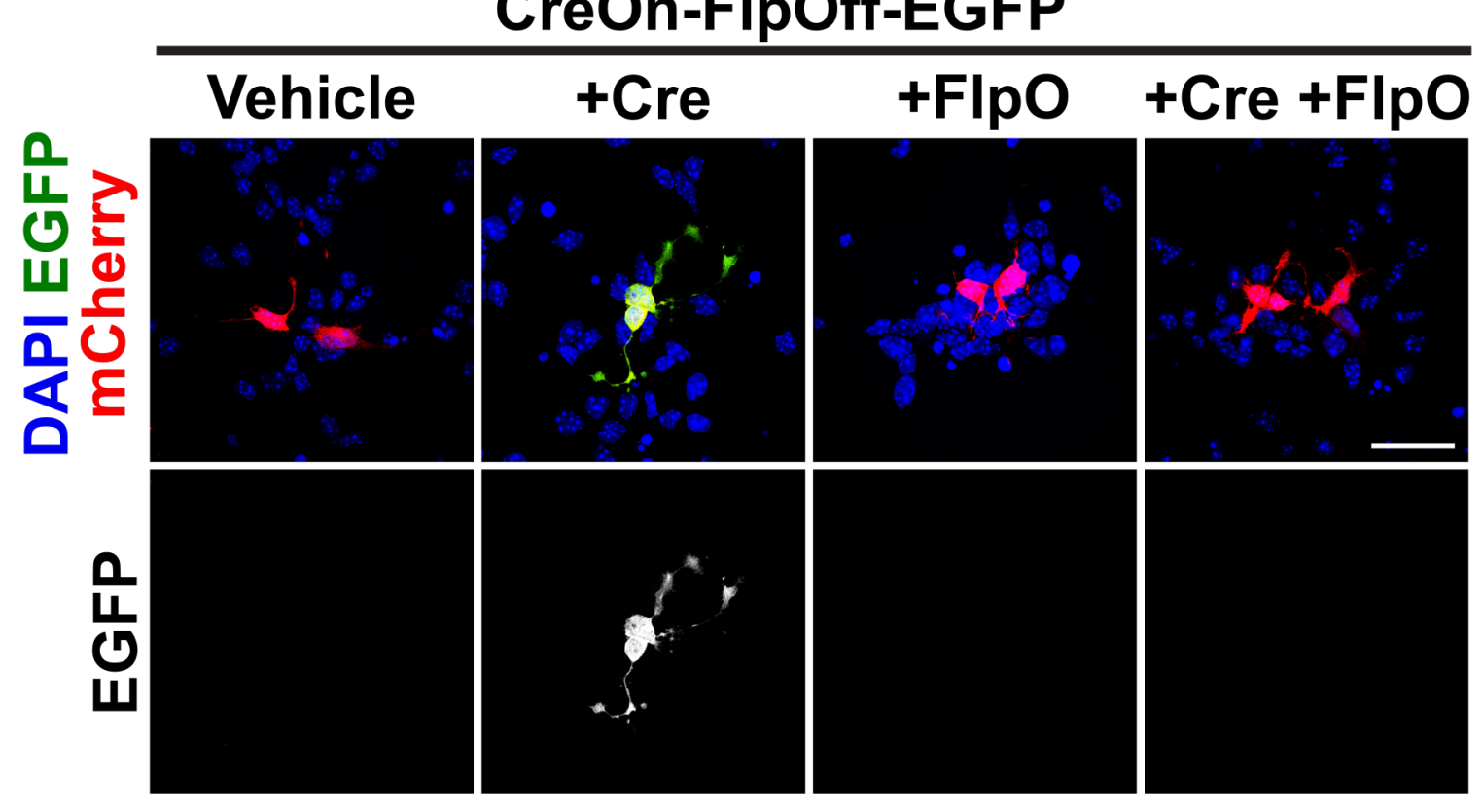

B

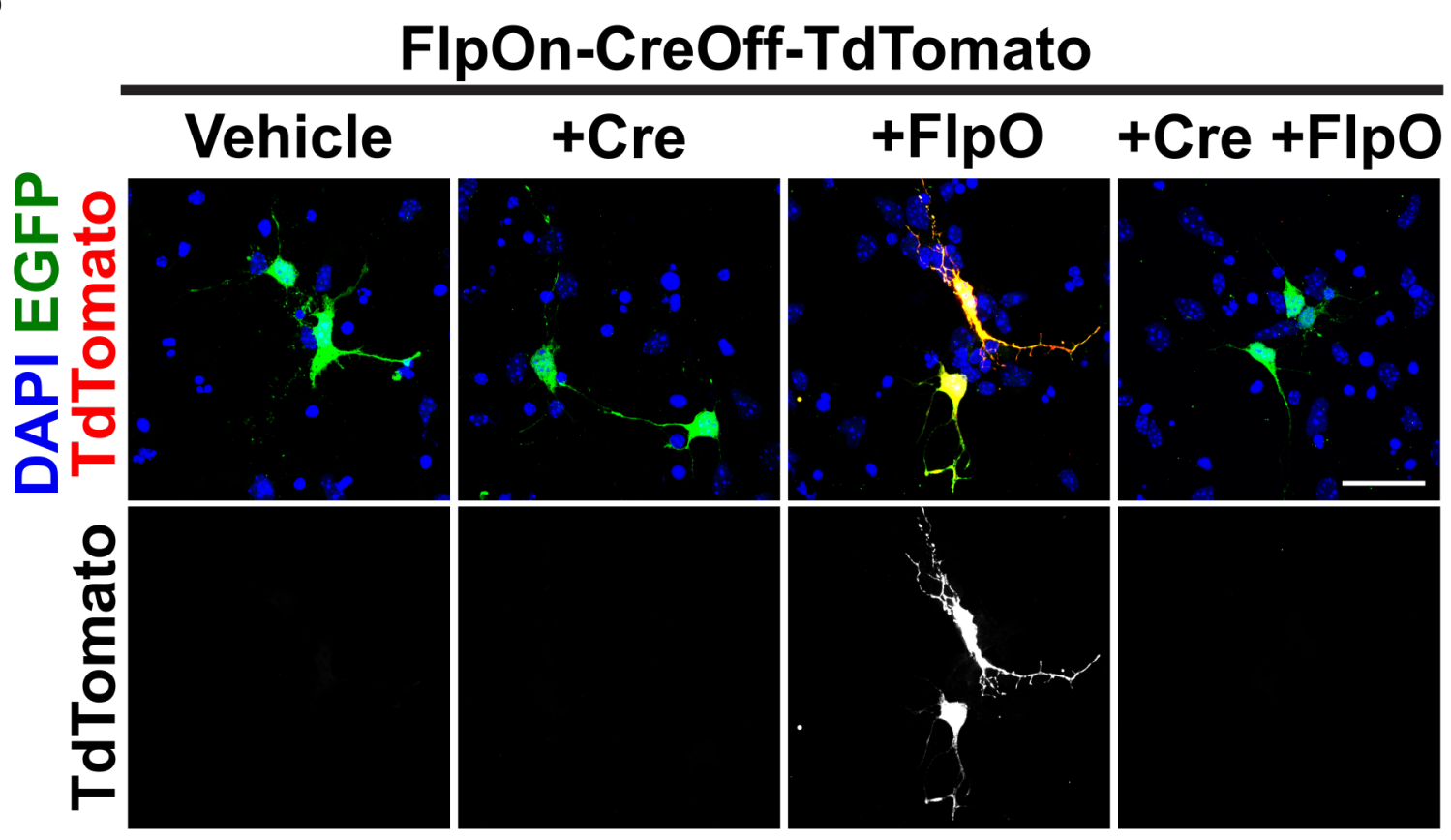

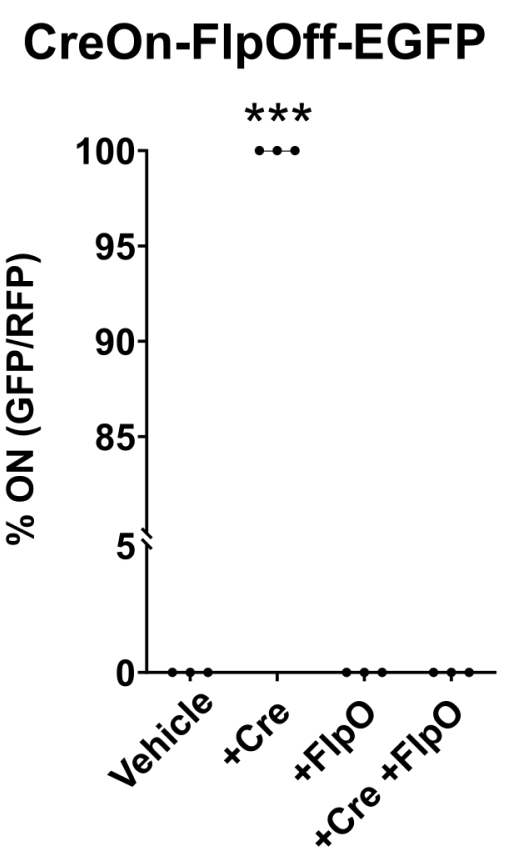

Constructs

FIpOn-CreOff-TdTomato

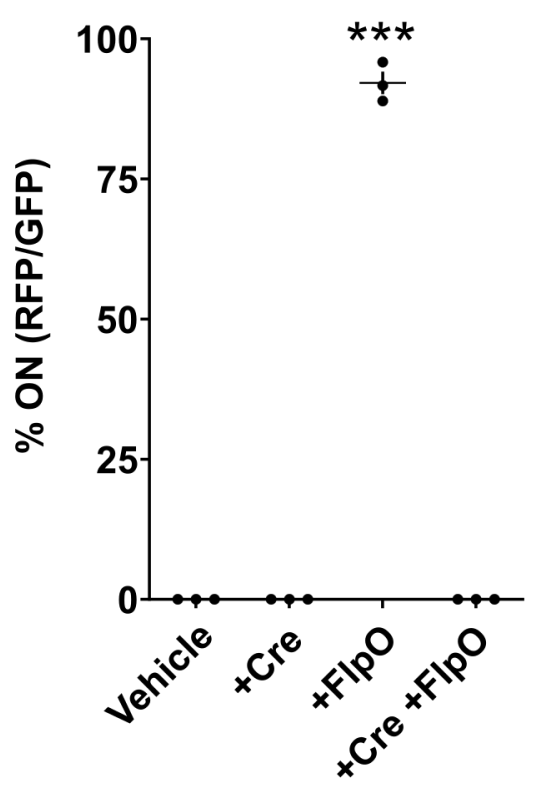

Constructs 
A

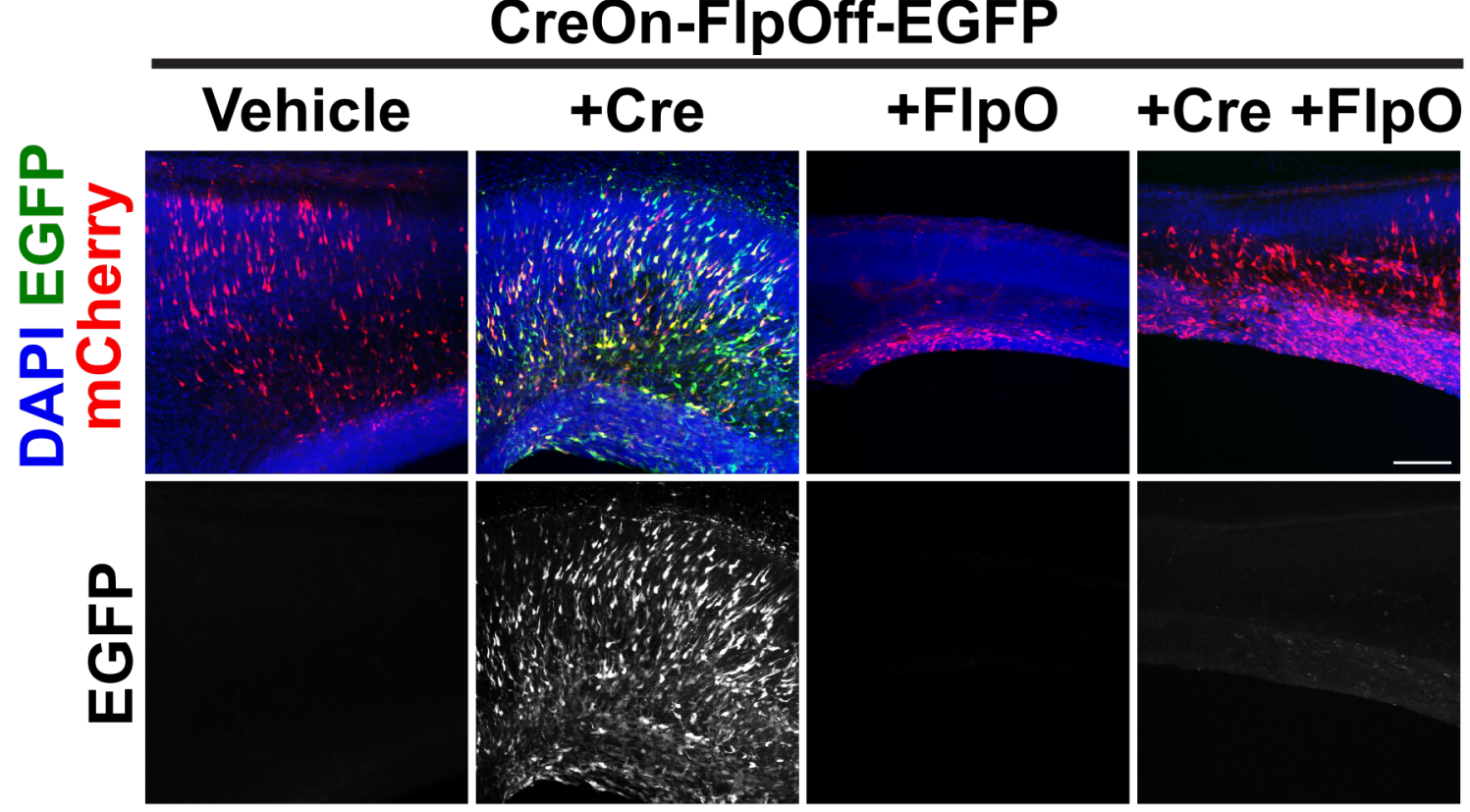

B

FIpOn-CreOff-TdTomato

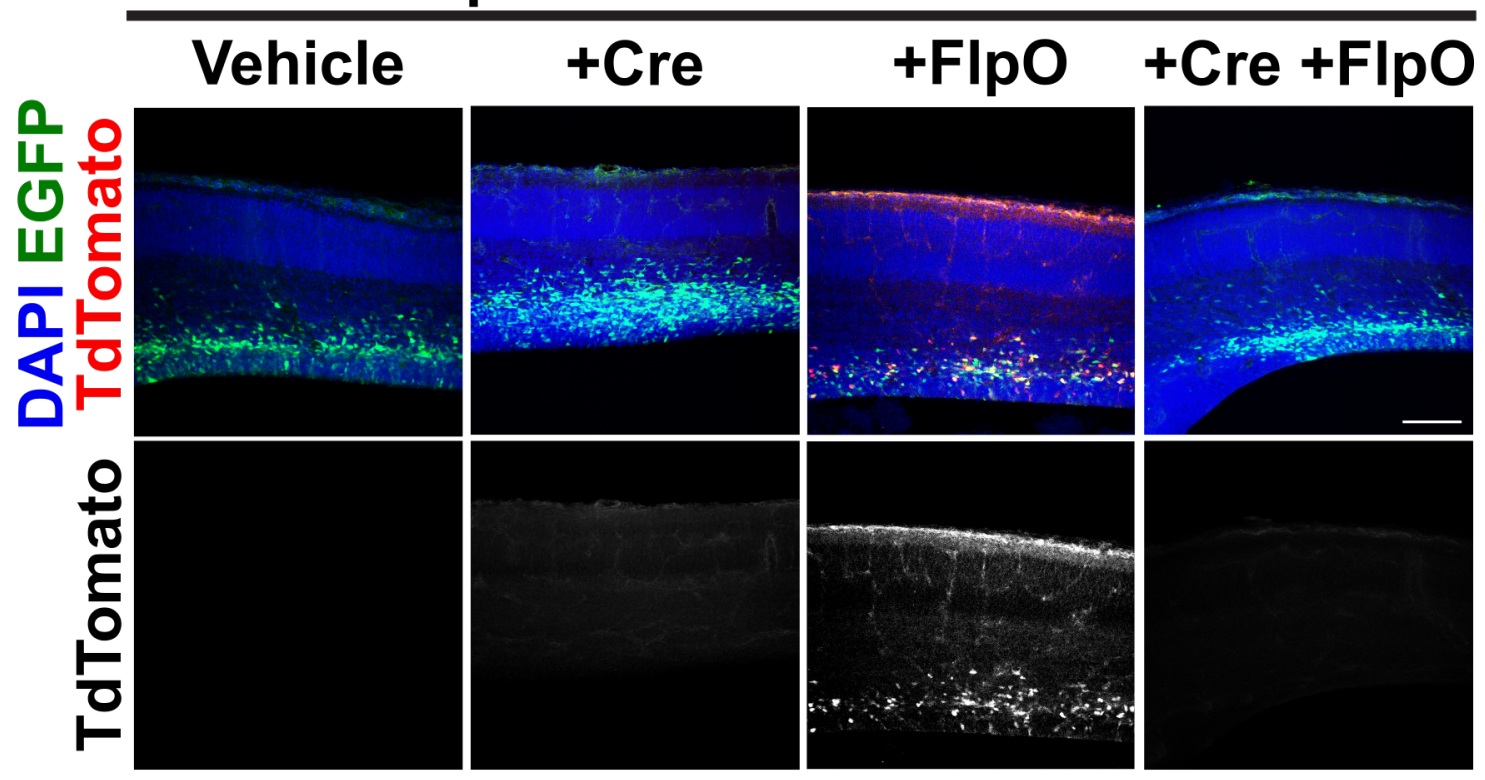

\section{CreOn-FIpOff-EGFP}

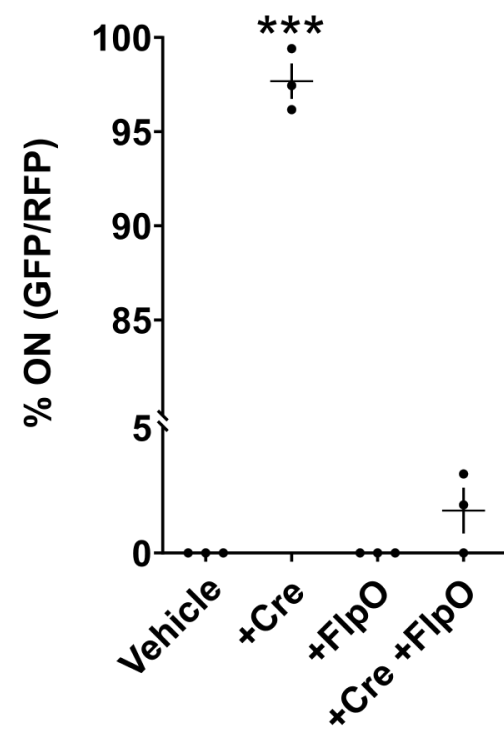

\section{Constructs}

FIpOn-CreOff-TdTomato

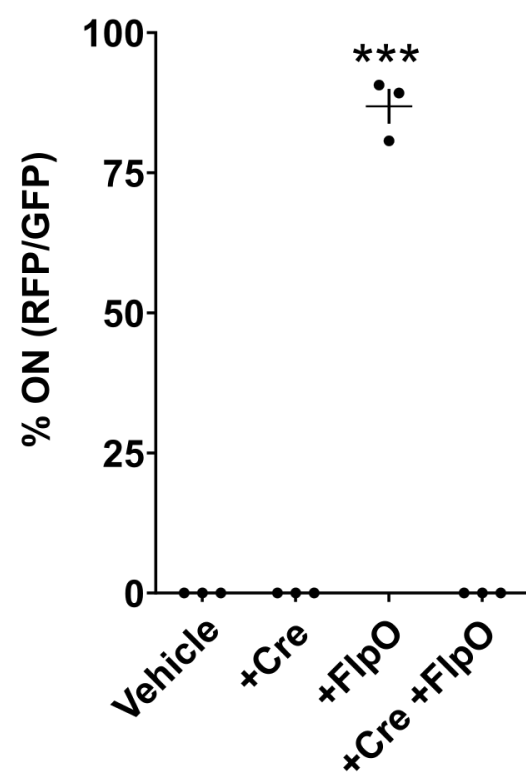

Constructs 
bioRxiv preprint doi: https://doi.org/10.1101/2020.07.28.224691; this version posted July 30, 2020. The copyright holder for this preprint (which was not certified by peer review) is the author/funder, who has granted bioRxiv a license to display the preprint in perpetuity. It is made available under aCC-BY-NC-ND 4.0 International license.

\section{AAV-CreON-FIpOff-EGFP}

\section{-Cre}
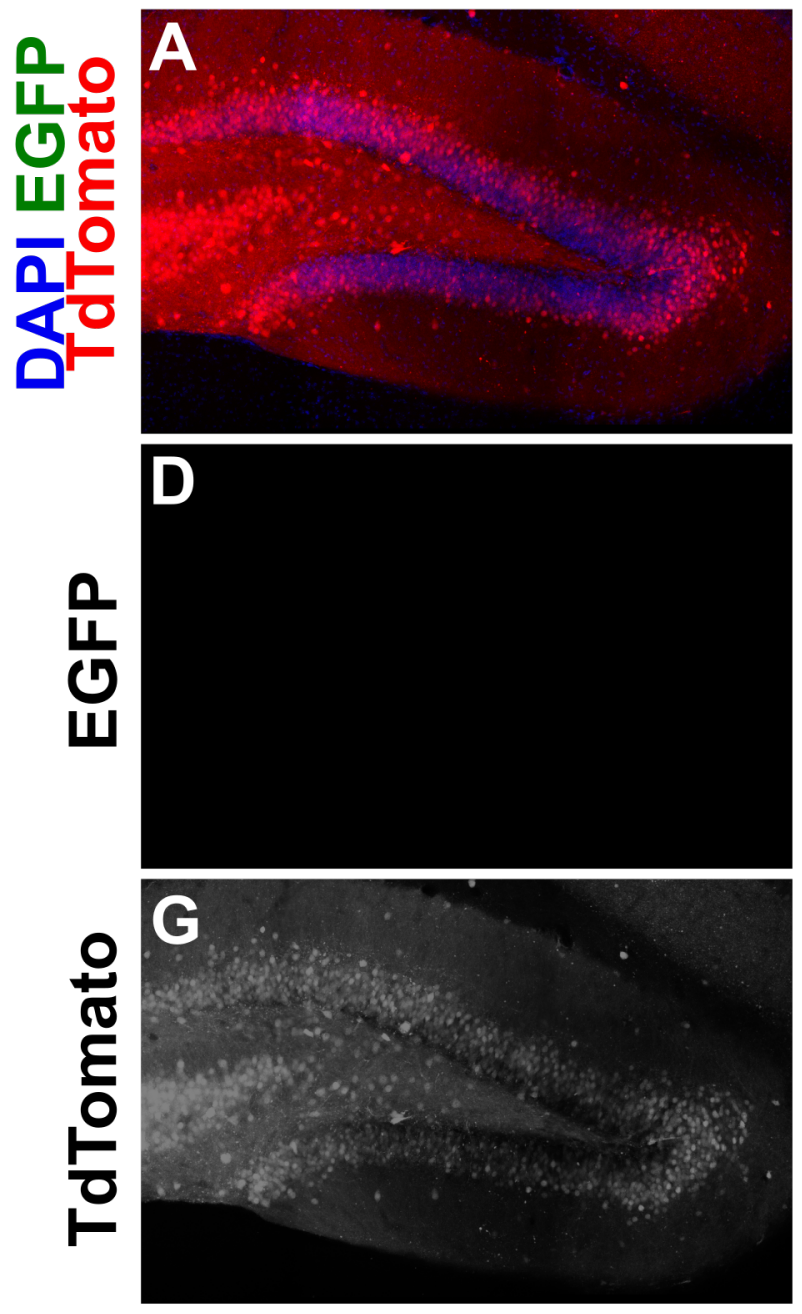

+ Cre
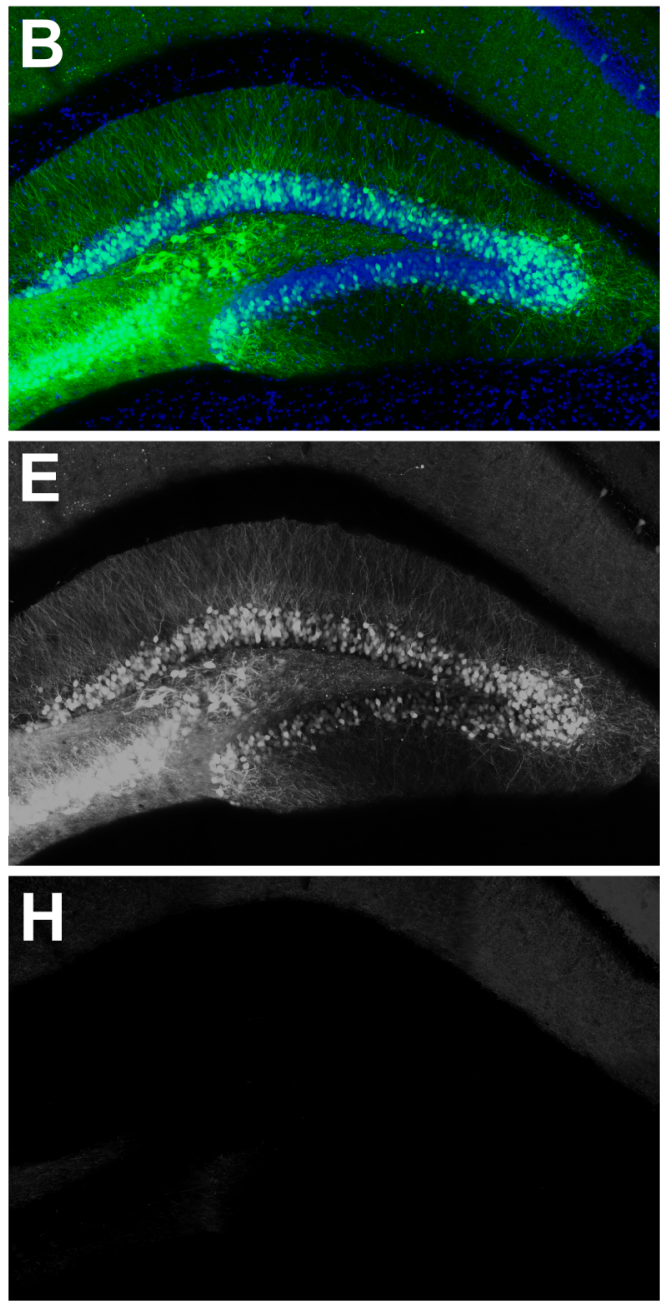

+Cre +Flp
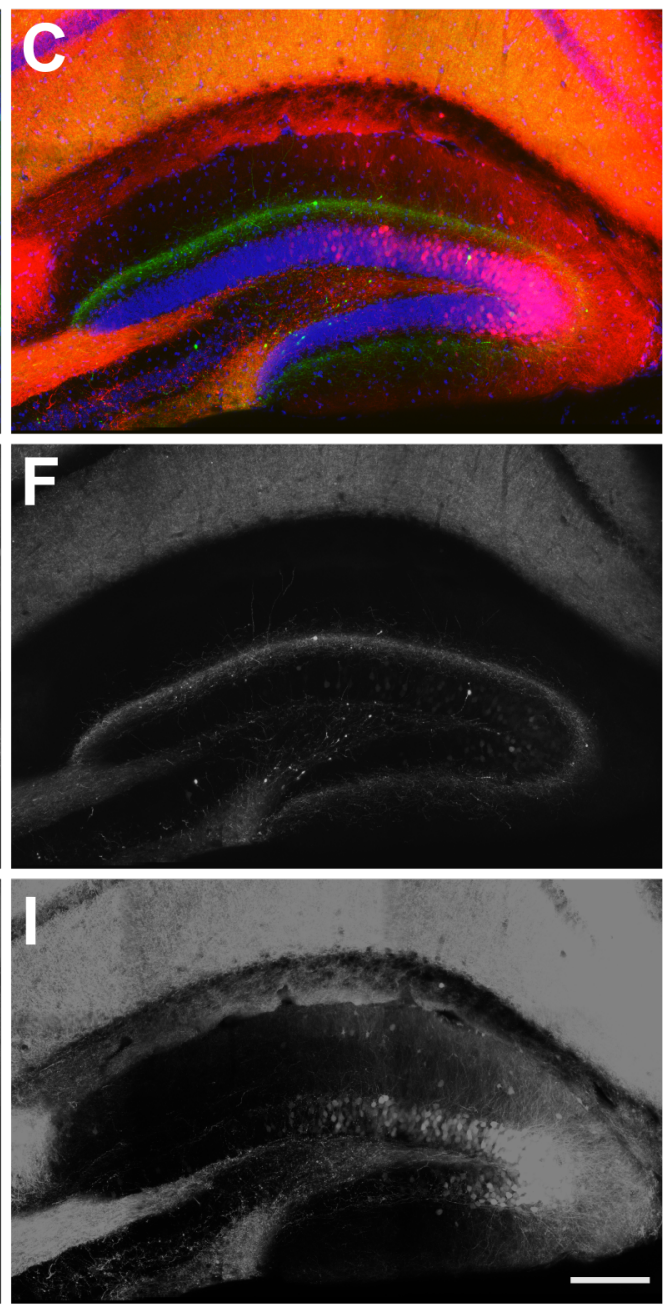
bioRxiv preprint doi: https://doi.org/10.1101/2020.07.28.224691; this version posted July 30, 2020. The copyright holder for this preprint (which was not certified by peer review) is the author/funder, who has granted bioRxiv a license to display the preprint in perpetuity. It is made available under ACC-BY-NC-ND 4.0 International license.

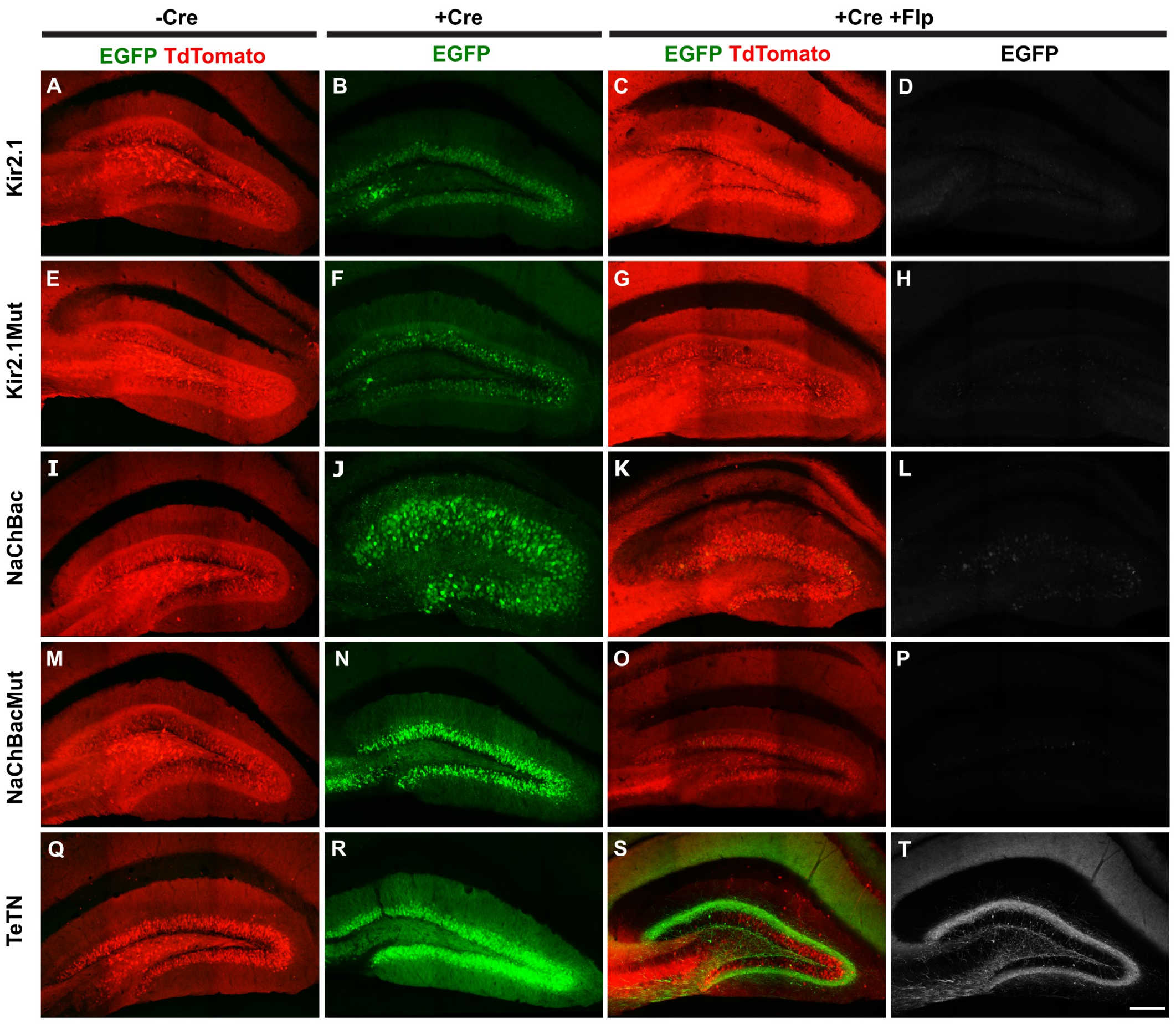

Fig7 


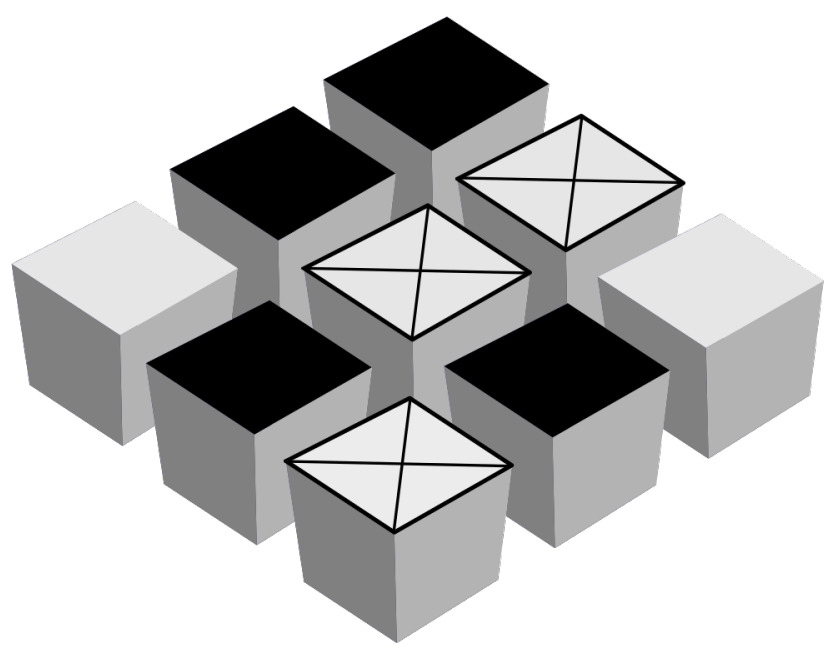

No recombinase

+ON recombinase

$\bigotimes+$ OFF Recombinase ( \pm ON)

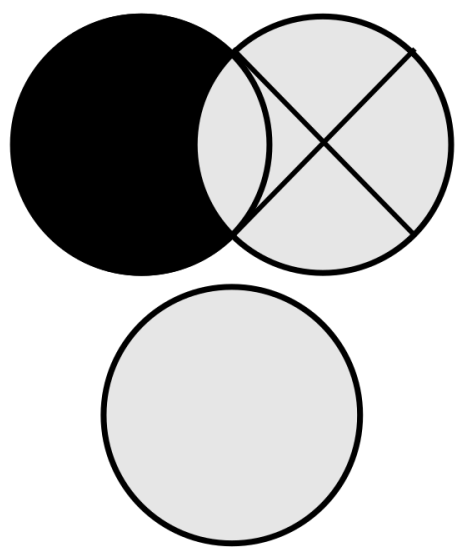

No Expression of GOI

Expression of GOI

\section{Expression of GOI}

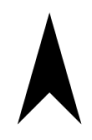

ON Recombinase

\section{Critical Period}

OFF Recombinase

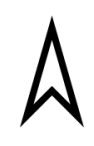

Experimental observation 